Atmos. Meas. Tech. Discuss., doi:10.5194/amt-2016-385, 2016

Manuscript under review for journal Atmos. Meas. Tech.

Published: 6 December 2016

(c) Author(s) 2016. CC-BY 3.0 License.

\title{
Noise characteristics in Zenith Total Delay from homogeneously reprocessed GPS time series
}

Anna Klos ${ }^{1}$, Addisu Hunegnaw ${ }^{2}$, Felix Norman Teferle ${ }^{2}$, Kibrom Ebuy Abraha ${ }^{2}$, Furqan Ahmed ${ }^{2 \#}$, Janusz Bogusz ${ }^{1}$

$5{ }^{1}$ Military University of Technology, Faculty of Civil Engineering and Geodesy, Warsaw, Poland.

${ }^{2}$ University of Luxembourg, Geophysics Laboratory, Luxembourg

\#Current address: Center for Space Research, University of Texas at Austin, USA.

Correspondence to: Anna Klos (anna.klos@wat.edu.pl), Addisu Hunegnaw (addisu.hunegnaw@uni.lu)

Abstract. Zenith Total Delay (ZTD) time series, derived from the re-processing of Global Positioning System (GPS) data, provide valuable information for the evaluation of global atmospheric reanalysis products such as ERA-Interim. Identifying the correct noise characteristics in the ZTD time series is an important step to assess the 'true' magnitude of ZTD trend uncertainties. The ZTD residual time series for 1995-2015 are generated from our homogeneously re-processed and homogenized GPS time series from over 700 globally distributed stations classified into five major climate zones. The annual peak of ZTD data ranges between 10 and $150 \mathrm{~mm}$ with the smallest values for the polar and Alpine zone. The amplitudes of daily curve fall between 0 and $12 \mathrm{~mm}$ with the greatest variations for the dry zone. The autoregressive process of fourth order plus white noise model were found to be optimal for ZTD series. The tropical zone has the largest amplitude of autoregressive noise $(9.59 \mathrm{~mm})$ and the greatest amplitudes of white noise $(13.00 \mathrm{~mm})$. All climate zones have similar median coefficients of AR(1) $(0.80 \pm 0.05)$ with a minimum for polar and Alpine, which has the highest coefficients of $\operatorname{AR}(2)$ $(0.27 \pm 0.01)$ and $\mathrm{AR}(3)(0.11 \pm 0.01)$ and clearly different from the other zones considered. We show that 53 of 120 examined trends became insignificant, when the optimum noise model was employed, compared to 11 insignificant trends for pure white noise. The uncertainty of the ZTD trends may be underestimated by a factor of 3 to 12 compared to the white noise only assumption.

\section{Introduction}

Continuous Global Navigation Satellite System (GNSS) observations, in particular those from the Global Positioning System (GPS), play a prominent role to help us improve our understanding of many of the Earth's internal and external processes. Especially the position time series have been widely employed to investigate various geophysical processes (van Dam et al., 1994; Larson et al., 1997; Wu et al., 2003; Sella et al., 2007; Teferle et al., 2009; Wöppelmann et al., 2009; Fu et al., 2013), which act on the Earth's surface and generally causing a measurable displacement of the GPS antenna. On the other hand, GPS has also proven to infer the conditions of the atmosphere, particularly in the lower and neutral (non-ionized) layer known as the troposphere, which plays an important role in generating both weather and climate (Rohm et al., 2014).

As the GNSS signal travels from the transmitting satellites to the ground-based receiver, it is subjected to variable atmospheric conditions. The atmosphere bends the signal causing a delay in the arrival time (path lengthening). In the troposphere this delay depends on the integral effect of the densities of dry air and water vapor along the entire atmospheric column. Because the amount of delay in the troposphere is directly related to the integrated observations of atmospheric conditions, including the amount of water vapor, GNSS can remotely sense integrated atmospheric water vapor (Bevis et al., 1992). The atmospheric products derived using GNSS observations can further be used to improve, e.g., the accuracy of forecasts generated by numerical weather prediction (NWP) models (e.g., Mahfouf et al., 2015; Wilgan et al., 2016).

The total atmospheric delay depends on the effective signal path between the satellite and receiver antennas and therefore indirectly on the satellite elevation angle, which provides a slant total delay as a function of the elevation angle. This slant 
Atmos. Meas. Tech. Discuss., doi:10.5194/amt-2016-385, 2016

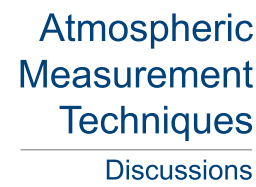

Manuscript under review for journal Atmos. Meas. Tech.

Published: 6 December 2016

(c) Author(s) 2016. CC-BY 3.0 License.

Discussions

total delay can be converted into an equivalent delay in the vertical (zenith) direction using a corresponding mapping function (MF) and is known as Zenith Total Delay (ZTD). Therefore, ZTD provides a measure of the integrated tropospheric state and it has been shown to be beneficial to separate it into two components: the Zenith Hydrostatic Delay (ZHD) and the Zenith Wet Delay (ZWD). Taking into account surface pressure and temperature, either from observations or an adequate

5 model, the ZTD can be converted using the ZWD into an estimate of the Integrated Water Vapor (IWV) content of the atmosphere (Bevis et al., 1992) and the amount of IWV has a direct relation to the change in temperature (Trenberth et al., 2003). Hence the use of ground-based near real-time GPS observations became quickly a popular research topic for weather forecasting. The use of GPS was further promoted its lower cost as compared to classical meteorological sensors, the establishment of various regional and global station networks, and activities related to the assimilation of the GPS-derived products in NWP models (Guerova et al., 2004; Walpersdorf et al., 2007; Dousa, 2010; Mahfouf et al., 2015; Kroszczynski, 2015; Guerova et al., 2016). Although the potential of the ground-based GPS-derived IWV products for climate studies was already acknowledged by Yuan et al. (1993), the long-term trend of IWV may be used as a proxy indicator of a possible change in climate, initially the number of studies remained relatively low (Hagemann et al., 2003). It is noted here that IWV plays a vital role in Earth's climate as it is tightly coupled with the temperature in the troposphere. This coupling drives a

15 positive feedback loop in climate modeling - making any temperature changes larger than they would be otherwise (Soden and Held, 2005)

As more GPS data have become available during the last two decades and the importance of homogeneous re-processing of the observations was acknowledged, interest in the long-term applications of the GPS-derived troposphere products has increased (Vey et al., 2009; Thomas et al., 2011; Bock et al., 2016). However, the long-term trend and stochastic properties of IWV (as derived from ZTD) remains a major source of uncertainty for a comprehensive understanding of the global climate system (Held and Soden, 2000). Multiple previous studies have shown that the noise characteristics of GPS-derived trend parameters from station position are not governed only by a white noise process (Johnson and Agnew, 1995) but are also affected by time-correlated noise (e.g. Langbein and Johnson, 1997; Mao et al., 1999; Williams et al., 2004; Teferle et al., 2008; Bos et al., 2013; Klos et al., 2016) . It is now widely accepted that if we assume only a white noise process affecting the GPS position time series, the uncertainties of the parameter estimates, particularly of the trend, would be underestimated by up to an order of magnitude. However, so far re-processed GPS observations have been used to estimate water vapor using white noise assumptions e.g. for analyzing meteorological events (Brenot et al., 2006; Bock et al., 2007; Nilsson and Elgered, 2008; Labbouz et al., 2013) for climate applications (Sguerso et al., 2013) and assimilation of ZTD in operational NWP models (Yan et al., 2009; Mahfouf et al., 2015). Therefore, identifying the correct noise characteristics in the ZTD/IWV time series is an important step in assessing the 'true' magnitude of ZTD/IWV trend estimates and is the prime objective of this study.

Climatologists have described the noise properties of any data interpreted in terms of climate as an autoregressive noise process (Matyasovszky, 2012). They have shown that this noise process gives better results compared to the simple white noise assumption. ZTD is directly linked to climate processes and one would expect that the same underlying noise model may fit as it does for other climate parameters, where the frequency spectra follow a well-defined fractal distribution, i.e., frequency and amplitude of the signal are related by means of an autoregressive process. This implies that the uncertainties of ZTD trends are also expected to increase compared to the white noise assumption. Consequently, the ZTD trends that have been provided in recent publications and which were used in climate studies may have been underestimated and should not be considered for future investigations. These considerations motivate us to undertake a comprehensive assessment of the stochastic properties of ZTD time series, thereby obtaining new estimates of ZTD trends and their uncertainties in addition to an improved understanding of the ZTD noise, that can be further interpreted in terms of climate, meteorological events and during potential assimilation in general circulation models in future. Therefore, the primary target of this study is to determine the most appropriate stochastic model for the ZTD time series on the basis of our recently homogeneously re- 
Atmos. Meas. Tech. Discuss., doi:10.5194/amt-2016-385, 2016

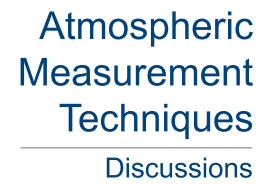

Manuscript under review for journal Atmos. Meas. Tech.

Published: 6 December 2016

(c) Author(s) 2016. CC-BY 3.0 License.

Discussions

processed GPS time series. These time series stem from over 700 globally distributed continuous GPS stations and cover the period 1995 to the end of 2015. The consortium of the British Isles continuous GNSS Facility (BIGF) and the University of Luxembourg TIGA Analysis Centres (BLT) have re-analyzed the full history of GPS data collected by a global tracking network of stations using the latest available models and methodology. While the temporal consistency of the time series is

5 addressed by keeping the bias models and processing methodology the same for the whole data period, the GPS position time series are often subjected to discontinuities which are either due to real position changes or other factors that do not necessarily reflect real geophysical events. Such uncorrected discontinuities are known to adversely affect trend estimates of the concerned position time series (Williams et al., 2003a; Thomas et al., 2011; Griffiths and Ray, 2015) and introduce random-walk noise into the time series (Williams, 2003b; Santamaria-Gómez et al., 2011).

10 In order to employ the ZTD time series for climate change studies, a homogenization of the ZTD time series, i.e. the need for identifying and correcting discontinuities, is necessary (Vey et al., 2009; Gazeaux et al., 2011; Ostini, 2012). While automated change detection methods have also been dedicated to GPS time series (Williams et al., 2003a; Khodabandeh et al., 2011; Gazeaux et al., 2013), identifying all discontinuities still requires significant visual inspection and manual intervention. For ZTD time series the detection of all discontinuities is particularly crucial as in most cases the climate signal

15 may be comparable in size to the magnitude of the amplitudes of the discontinuities. Furthermore, undetected discontinuities in the ZTD time series may also introduce a component of random-walk noise.

Our investigation of the noise processes in ZTD time series is based on the climate zones following the Köppen-Geiger classifications (Peel et al., 2007). In this study we focus on five climate zones for classifying the world's climate based on the annual and monthly averages of temperature and precipitation. These five major climate zones are tropical, dry, temperate, continental and polar and Alpine. It is noted here that one can also investigate the noise process of ZWD or the IWV time series, which are arguably more linked with the water vapour variability in the atmosphere. However, firstly, a pre-analysis showed that the stochastic properties of the ZWD and ZTD time series are nearly identical (see Figure S1 as part of the supplementary material) and, secondly, the preferred product for assimilation in NWP models are the ZTD estimates and not the IWV estimates. To convert the GNSS derived ZWD to IWV, a water vapour mean temperature parameter at a GPS

25 station is required. However, the source of this parameter varies; it can be estimated from empirical model or from observed surface temperature. Thus the accuracy of this parameter introduces an error in the trend estimates (Nilsson and Elgered, 2008). Recent extensive studies by (Wang, 2016) have demonstrated that depending on the choice of the source of the water vapour mean temperature parameter, the IWV trend shows a relative error larger than $10 \%$. Thus, for consistency ZTD should be converted to IWV once it has been assimilated and we argue that this would also be the best way forward for climate models.

Finally, the paper is divided into five different sections. The ZTD estimation from GPS, the GPS data processing strategy, the detection of discontinuities in the ZTD time series and the homogenization (verification and correction) process are described in section 2. The ZTD time series parametric model and the features of the estimated periodic signals are explained in section 3. The main results of the study, the noise analysis, is covered in section 4 . Section 5 discusses the core results and section 6 provides the conclusions of the paper.

\section{Methodology}

In the following section, we describe the GPS data processing strategy employed which provided the homogeneous daily GPS solutions for this study, including the modelling and estimation of the ZTD values. We detail the homogenization strategy applied to the ZTD time series and finally describe the ZTD noise models we have investigated. 
Atmos. Meas. Tech. Discuss., doi:10.5194/amt-2016-385, 2016

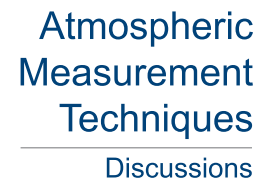

Manuscript under review for journal Atmos. Meas. Tech.

Published: 6 December 2016

(c) Author(s) 2016. CC-BY 3.0 License.

Discussions

\subsection{GPS data processing and ZTD estimation}

The International GNSS Service (IGS) (Dow et al., 2009) recently completed the second re-processing campaign (repro2). Using the latest available bias models and methodology the different IGS analysis centers (ACs) re-analyzed the full history of GPS data collected by the global tracking network from 1995-2015. At the University of Luxembourg, as part of our IGS

5 Tide Gauge Benchmark Monitoring (TIGA) Working Group activities, we completed a new global solution using up to 750 GPS stations. Figure 1 shows a map of 120 selected stations for which we will present our results. As it can be seen, the stations are globally distributed and the time series used vary from 6 to 21 years in length.

The re-processing follows a double difference network strategy using the Bernese GNSS Software version 5.2 (BSW52) (Dach et al., 2015), incorporates recent bias model developments, the latest International Earth Rotation and Reference

10 Systems Service (IERS) 2010 conventions (Petit and Luzum, 2010) and IGS recommendations. Further details are detailed in (Hunegnaw et al., 2016). The selected station network included all IGb08 core stations (Rebischung et al., 2012) and more or less the complete archive of TIGA, which encompasses a large number of GPS stations at or near the global network of tide gauges. The GPS data was re-processed using the Centre for Orbit Determination in Europe (CODE) final precise orbits and Earth orientation parameters. We employed the IGS08 satellites and receiver antenna phase center models and adopted an

15 elevation cut-off angle of $3^{\circ}$ (Dach et al., 2016).

During GNSS processing the tropospheric propagation delay $\left(T_{r}\right)$ affecting the GPS observation in the line of sight, is modeled as:

$T_{r}=m f_{h}(e) Z H D+m f_{w}(e) Z W D+m f_{g}(e)\left[G_{N} \cos (\alpha)+G_{E} \sin (\alpha)\right]$

where $e$ is the elevation angle in the topocentric coordinate frame to the GPS satellite and $m f_{h}$ and $m f_{w}$ are the hydrostatic and wet MFs, respectively. These are used to map the excess propagation paths for the slanted signals that arrive at the GPS antenna to the zenith direction, i.e. the direction with minimal tropospheric delay. The temporally averaged $T_{r}$ then provides the ZTD estimate for a given epoch. There are varieties of MFs, which are all based on the continuous fraction form as was initially proposed by Marini (1972). Here we make use of the Vienna Mapping Function 1 (VMF1) (Böhm et al., 2006) that allows the MF to describe the atmosphere with the finest detail, leading to the highest precision in the derived tropospheric parameters. This is achieved by the MF by taking into account different factors such as the Earth curvature at different latitudes and seasonal changes. The VMF1 coefficients of the continuous fraction form are derived from the pressure-level data estimated by European Centre for Medium Range Weather Forecasting (ECMWF) (Simmons and Gibson, 2000) and are given every 6 hours on a global $0.75^{\circ} \times 0.75^{\circ}$ grid. The third term in equation (1) represents the gradient (tilt) corrections in North-South direction (GN) and in East-West direction (GE), $\alpha$ is the azimuth angle defining azimuthal asymmetry in the troposphere and $m f_{g}$ is the gradient MF (Chen and Herring, 1997).

In BSW52 the ZHD is parameterized as a piece-wise function variation of the delay using a piecewise linear interpolation between temporal nodes. Observations of atmospheric pressure at the GPS station offer high precision for the ZHD estimates and minimize station height errors (Tregoning and Herring, 2006). However, many of the TIGA and IGS stations do not possess integrated meteorological sensors. Thus, ZHD in units of meters was a priori obtained reliably from surface pressure data from the gridded output of the ECMWF NWP model and is provided by VMF1 using the modified Saastamoinen model, which assumes that the atmosphere is in hydrostatic equilibrium (Davis et al., 1985). We estimate the ZTD parameters in an interval of 1 hour with a loose constraint of 5 meters. In addition, horizontal gradients in the North-South and East-West directions are estimated in a 24 hour interval with the same 5 meter loose relative constraint.

In this manner more than two decades of ZTD time series along with station positions are available from our re-processing.

40 Figure 1 shows a selection of 120 global stations for which we have carried out the further analysis described in this study. However, as the station positions are affected by on average two discontinuities per station per decade, the ZTD time series need to be homogenized before they are useful for further application. 
Atmos. Meas. Tech. Discuss., doi:10.5194/amt-2016-385, 2016

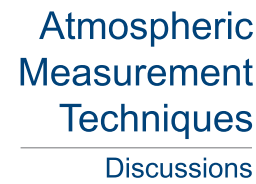

Manuscript under review for journal Atmos. Meas. Tech.

Published: 6 December 2016

(c) Author(s) 2016. CC-BY 3.0 License.

Discussions

(c) $($ P)

\subsection{Homogenization of ZTD time series}

The ZTD parameter is now customarily derived from the processing of the GPS observations but its consistency in time is adversely affected by a number of processes, particularly discontinuities that may or may not stem from real geophysical or climatic signals (Beaulieu et al., 2008; Gazeaux et al., 2011; Gazeaux et al., 2013; Bock et al., 2014; Griffiths and Ray,

5 2015). The source of these discontinuities can have many origins but is mostly related to hardware changes (receiver, antenna or antenna cable), changes in the observation procedures (e.g. the elevation cut-off), modifications in the vicinity of the GPS antenna (e.g. introduction/removal of signal obstructions), real physical displacements of the antenna (e.g. earthquakes) and other mostly unknown sources. Homogenization is the technique of detecting, verifying and correcting of these discontinuities in the ZTD or station position time series. Undetected discontinuities with significant amplitudes adversely affect the estimated parameter of interest from the time series, especially any trend estimates as a central component for many geodetic, geophysical and climatic investigations. Recently a working group was concerned with this topic under the umbrella of the IGS: Detection of Offsets in GPS Experiment (DOGEx). This working group aimed at consistently and objectively detect discontinuities in GPS time series in an automated fashion while drawing on the experiences of both the geodetic and climatic scientists. The experiment concluded that there was no single algorithm that could fully automate and reliably detect all discontinuities in GPS time series (Gazeaux et al., 2013). Furthermore, for the best results a manual intervention was necessary in order to detect particularly those offsets of unknown causes.

In our re-processing that covers a period of 20 years we have identified approximately 2500 discontinuities in the position time series for the 750 stations. As the scatter in the ZTD time series is much larger than in the position time series our strategy was to first identify the position offsets and then adopt the related epochs also for our offset modeling of the ZTD time series. In this way the discontinuity identification and verification is based on (1) the International Terrestrial Reference Frame 2008 (ITRF2008) supplied discontinuity file, (2) earthquakes reported by the USGS Earthquake Hazards Program (https://earthquake.usgs.gov/) and (3) a manual inspection of all the position time series. The obtained discontinuity budget arises in $67 \%$ from hardware changes, in $4 \%$ from earthquakes and in $29 \%$ from unknown origins. When all epochs of offsets were taken into consideration, we found a maximum offset amplitude in the ZTD time series of $83.54 \mathrm{~mm}$, a maximum improvement in the standard deviation of $1.56 \mathrm{~mm}$, and a maximum, most dramatic, change in ZTD trend of 3.7 $\mathrm{mm} /$ decade at station POHN (Pohnpei, Federated States of Micronesia). Table S1 in supporting information shows statistics related to the detected discontinuities in the ZTD time series of the 120 GPS stations discussed in this study.

\subsection{ZTD time series modelling}

30 The ZTD time series are commonly modeled with least-squares or weighted least squares estimation when uncertainties of individual observations are taken into account. Focusing on the estimation of trend, which is interpreted in terms of climate change (e.g., Nilsson and Elgered, 2008), and all significant periodics, derived from a spectral analysis, one can fit a leastsquares model as:

$$
\begin{aligned}
Z T D\left(t_{i}\right) & =Z T D_{R}+v \cdot\left(t_{i}-t_{R}\right)+\sum_{k=1}^{6}\left[S_{k} \cdot \sin \left(2 \pi \cdot f_{k} \cdot\left(t_{i}-t_{R}\right)\right)+C_{k} \cdot \cos \left(2 \pi \cdot f_{k}\left(t_{i}-t_{R}\right)\right)\right]+ \\
& +\sum_{j=1}^{n}\left(d_{j} \cdot H\left(t_{i}, t_{j}\right)\right)+\varepsilon_{Z T D_{i}}
\end{aligned}
$$

where $t_{i}$ is time, $t_{R}$ is the reference time, $Z T D_{R}$ the initial value of the ZTD at time $t_{i}=t_{R}, v$ is the linear trend, $C_{k}$ and $S_{k}$ are the coefficients of the harmonic terms and $\varepsilon_{Z T D}$ is the stochastic part, $d_{j}$ represents the discontinuity which occurs at time $t_{i}, k$ is the number of harmonic terms and $f_{k}=(1 / 365.25,2 / 365.25,3 / 365.25,4 / 365.25,1,1 / 2)$ is a frequency in days. We apply here 
Atmos. Meas. Tech. Discuss., doi:10.5194/amt-2016-385, 2016

Manuscript under review for journal Atmos. Meas. Tech.

Published: 6 December 2016

(c) Author(s) 2016. CC-BY 3.0 License. part $\varepsilon$. The model in equation (2) also accounts for discontinuities using a Heaviside function, $H$. The amplitudes of the harmonic terms $\left(A_{k}\right)$ and their corresponding phases $\left(\phi_{k}\right)$ are:

$$
\begin{aligned}
& A_{k}=\sqrt{S_{k}^{2}+C_{k}^{2}}, \\
& \phi_{k}=\tan ^{-1}\left(\frac{S_{k}}{C_{k}}\right), \quad k=1, \ldots, 6
\end{aligned}
$$

5 The unknown parameters in equation (2) are estimated using least-squares incorporating more than two decades of data with 1-hour sampling interval. In solving equation (2), the disagreement between model and real data are formed as uncorrelated white noise. In this case, the weight matrix $\mathbf{P}$ is a diagonal matrix based on the uncertainties of individual observations, $\mathbf{A}$ is a design matrix of (2) and y is a vector of observations. The estimated parameters, vector $\mathbf{X}$, are then obtained as:

$$
\mathbf{X}=\left(\mathbf{A}^{T} \mathbf{P A}\right)^{-1} \mathbf{A}^{T} \mathbf{P y}
$$

10 The covariance matrix of the fitted parameters is then equal to:

$$
\mathbf{C}_{\mathbf{x}}=\left(\mathbf{A}^{T} \mathbf{P A}\right)^{-1}
$$

Here, the uncertainties of both trend and seasonal signals are determined with the assumption of uncorrelated residual or white noise only (Morland et al., 2009). Even the values of the ZTD errors of the individual observation have little impact on the results of the estimated parameters and their uncertainties. Nilsson and Elgered (2008) added a short term correlation to the covariance matrix $\mathbf{C}_{\mathbf{X}}$ to consider a colored noise. They found that the uncertainties of IWV trends increased by a factor of four when a correlation is added. Combrink et al. (2007) took a further step and proposed an autoregressive moving average (ARMA) noise model, which better represents the correlation of IWV in time than a simple white noise assumptions.

In general, the first order $\operatorname{ARMA}(1,1)$ noise model is defined as:

$$
\varepsilon_{i}=\phi \varepsilon_{i-1}+\theta Z_{i-1}+Z_{i}
$$

where $\varepsilon$ is the residual ZTD, obtained by removing the trend, offsets and the seasonal components from the reprocessed ZTD time series. The symbols $\phi$ and $\theta$ are the autoregressive (AR) and moving average (MA) parameters, respectively, $Z_{i}$ is a Gaussian variable with fixed standard deviation. Combrink et al. (2007) examined the power spectral densities (PSDs) of two South African GPS stations and pointed out that IWV trend uncertainty increased by twofold when ARMA $(1,1)$ is applied. Most time series may also be expressed by a specific class of ARMA model, an autoregressive fractionally integrated moving average (ARFIMA) noise model. A ZTD residual time series, $\varepsilon_{Z T D}(t)$, follows $\operatorname{ARFIMA}(p, d, q)$, if it is governed by the following relationship (e.g., Sowel, 1992):

$$
\Phi(L)(1-L)^{d} \varepsilon_{\text {ZTD }}(t)=\Theta(L) w_{t}
$$

where $L$ is the lag operator and $w_{t}$ is uncorrelated white noise. The parameters $\Phi$ and $\Theta$ are estimated as:

$$
\begin{aligned}
& \Phi(L)=1-\phi_{1} L^{1}-\phi_{2} L^{2}-\ldots-\phi_{p} L^{p} \\
& \Theta(L)=1+\theta_{1} L^{1}+\theta_{2} L^{2}+\ldots+\theta_{q} L^{q}
\end{aligned}
$$


Atmos. Meas. Tech. Discuss., doi:10.5194/amt-2016-385, 2016

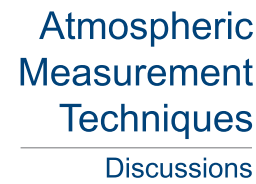

Manuscript under review for journal Atmos. Meas. Tech.

Published: 6 December 2016

(c) Author(s) 2016. CC-BY 3.0 License.

Discussions

(c) $\underset{\text { BY }}{(i)}$

$\operatorname{ARFIMA}(p, d, q)$ can be implemented in different ways, depending on the AR, FI and MA parameters: $p, d$ and $q$, respectively. We can start from a simple $\operatorname{AR}(1)$ model with $p=1$, which means, that there are no FI and MA parameters, i.e., $d=0$ and $q=0$ :

$z_{i}=\phi_{1} z_{i-1}$

5 getting through the MA part by estimating its order and ending with an autoregressive fractionally integrated moving average $\operatorname{ARFIMA}(p, d, q)$ model, where $\mathrm{d}$ is the integer order of the differencing of data before we estimate its stationarity. When the $\operatorname{ARFIMA}(p, d, q)$ noise model is being computed with Maximum Likelihood Estimation (MLE), $\mathrm{p}$ should be smaller than 5 (Bos et al., 2012). A simple AR(1) model means that any data sample is being dependent only on the previous observation. When we increase AR into fourth order (AR(4)), it expands our search for any dependencies that exist between current and the four previous values.

\section{Results}

In the following section, we present results of seasonal signals: annual, semi-annual, three and four months terms were analyzed along with daily and sub-daily oscillations. We include all above mentioned periodics, as they affect noise analysis if unmodelled. Having modelled the deterministic part, we present the results of noise analysis and compare different noise processes. We end with recommendation on the optimum noise model to be used for any future analysis of Zenith Total Delay taking into account the differences according for the given climate zone.

\subsection{Temporal variations of ZTD}

In this study, we considered 120 stations with ZTD time series lengths between 6 and 21 years stemming from our reprocessed global network of stations (Figure 1). On average, each of the time series is characterized to contain 2 offsets. For interpretation the stations are classified into five different climate zones: tropical, dry, warm temperate, continental and polar and Alpine based on the general Köppen-Geiger climate classification (Peel et al., 2007), Figure 2. We did not follow the detailed Köppen-Geiger climate classification which contains 27 different climate sub-zones, as we will not have a representative sample of stations from each of them to make the sub-zones statistically significant. We also focused on those climate zones with stations distributed all around the globe to investigate which noise model is optimal for any climate conditions we may consider. Having classified our dataset of 120 stations we ended up with a station number of 27 in the tropical, 13 in the dry, 35 in the warm temperate, 22 in the continental climate, and 23 in the polar and Alpine zones. These numbers provide a statistically significant results for both temporal variations and noise parameters we derive in the following study.

Any individual ZTD time series can behave in different ways, due to the region where station is located. Typically, the tropical zone is characterized by high day-to-day anomalies of GPS derived ZTD time series (e.g., Jin et al., 2008). Oceanic coasts are thought to have greater annual variations than any other regions (e.g., Jin et al., 2007), while regions between $20^{\circ}$ and $65^{\circ}$ for both Hemispheres ( $\mathrm{N}$ and $\mathrm{S}$ ) are characterized by large values of PWV linear trends of $4 \mathrm{~kg} / \mathrm{m}^{2}$ per decade determined for PWV from the European Reanalysis Interim (ERAI) model and DORIS data (Bock et al., 2014). This might be a reason to suggest that the ZTD residuals $\varepsilon_{Z T D}$, or their stochastic model from equation (2) behave in different ways for each climate zone examined. This could arise from variations in concentrations in the hydrostatic and wet parts of the atmosphere which are associated with the zone. As an example, the polar regions are very dry, which results in a small amount of water vapor and in this way a low impact on the wet part of the ZTD. Besides, the high-frequency part of the residuals reflects local station effects (e.g. multipath). This is why each of the ZTD time series may have different characteristics. Hence, we examined the Power Spectral Densities (PSDs) of each of the analyzed stations. Figure 3 shows a 
Atmos. Meas. Tech. Discuss., doi:10.5194/amt-2016-385, 2016

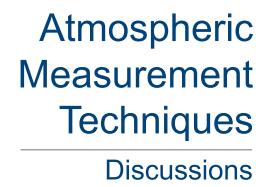

Manuscript under review for journal Atmos. Meas. Tech.

Published: 6 December 2016

(c) Author(s) 2016. CC-BY 3.0 License.

Discussions

PSD for a single selected station, BJFS (Beijing, China) for both original and residual ZTD time series. We have found that 1-hour ZTD time series are characterized by clear peaks of one year and three subsequent overtones in addition to the diurnal and semi-diurnal peaks. The annual oscillation is the most powerful peak for all examined stations, followed by the semiannual oscillation, which is roughly half the magnitude as the annual one for $70 \%$ of the stations. Peaks of 3 and 4 cpy

5 (cycles per year) are clearly seen in the frequency domain for low- and mid-latitude stations, while these are hardly noticeable for the polar and Alpine zones. In this way, we assumed a seasonal model containing all 6 periodicities (equation 2 ), adding diurnal and sub-diurnal peak to above mentioned.

Figures 4 and 6 as well as Table 1 summarize the results for the annual amplitudes. In general, the main seasonal signal for the selected stations varies between 10 to $150 \mathrm{~mm}$ with a median of $50 \mathrm{~mm}$. Low- and mid-latitudes stations are 10 characterized by larger annual variations than high-latitude stations, especially those in the Southern Hemisphere (SH) located in polar and Alpine regions. The Northern Hemisphere (NH) is characterized by maxima in July to August (phase shift of annual signal corresponding to $200^{\circ}$ ), while the Southern Hemispheres maxima fall between January and February (phase shift of $20^{\circ}$ ). There is no obvious correlation between annual amplitudes for different climate zones, except the fact that, amplitudes for tropical and warm temperate stations are higher than those located in continental zones. Again with exceptions, oceanic coastal stations show higher annual changes than those of inland stations. Stations in East Asia (BJFS, IISC, KUNM), Japan (TSKB, P211) and East coast of North America (STJO, BRMU, SCH2, WES2, NRC1, GODE, ALGO, MOB1) show larger annual amplitudes compared to other stations. This was also noticed by Jin et al. (2007). The area of India is characterized by monsoon, what may cause such a large variation during one year. Brazil is included in the tropical zone, however, stations on the coast of Brazil have different phases from inland stations. As the coastal zone in the northeast of Brazil is fairly dry, this might be a reason why these tropical stations differ a lot. Interesting to note here is that, even though the Antarctic and Arctic regions are classified into the same major climate zone, i.e. the polar and Alpine, the annual amplitudes of the Antarctic stations show notably lower amplitudes than Greenland stations - an indication of low variability in ZTD. However, in the detailed climate classification according to Köppen-Geiger, the major Alpine climate zone is further subdivided into two sub-zones, that match the significant different variabilities we see in our annual ZTD amplitudes between those two regions. The stations in NH are located mostly in Greenland, so the higher annual signal we noticed here might arise from the their coastal location and the impact of the Gulf Stream, which results in warmer waters along the Southern coast of Greenland than that of Antarctica. Due to above, we decided to split the polar and Alpine zone into two sub-zones of Northern and Southern Hemisphere. We reflected this division in Table 1.

Figure S2 in supplementary information shows the semi-annual signal for a set of 120 analyzed stations. Here, a phase of semi-annual peak is presented. All stations show a very good consistency of phase. Maxima of almost all stations fall in January, excluding tropical for which the majority of maxima fall in May. Again, few exceptions can be also found in dry regions: MAS1 (Maspalomas, Gran Canaria), TAMP (Tampico city, Mexico), RAMO (Ramon, Israel), LPAZ (La Paz, Mexico) and AREQ (Arequipa, Peru), for which the first maximum falls in March.

We also investigated the diurnal to semi-diurnal cycles of the series, since the ZTD time series have a 1-hour resolution. The diurnal cycle reflects day-to-day changes caused by the solar cycle along with changes in temperature and rainfall. Figures 5 and 7 as well as Table 1 summarize the results for the diurnal amplitudes for the selected set of analyzed ZTD time series. The phase shifts are given with respect to the local meridian. The largest diurnal peaks were found for stations located in low-latitude regions, especially tropical and dry zones, and are approximately 5-10 times higher than for other climate zones. The warm temperate diurnal amplitudes fluctuate between 1 and $7 \mathrm{~mm}$ with maxima for South American stations. The diurnal amplitudes for the continental zone do not vary very much on a station-by-station basis, while the diurnal signals for the polar and Alpine regions are almost flat with amplitudes close to zero. The time of diurnal maxima is consistent and very homogenous for stations located in Europe. The mean peak time is around 18 hours with respect to the local meridian. The times of peaks beyond the area of Europe seem inconsistent, however, the majority are between 18 and 24 hours. The 
Atmos. Meas. Tech. Discuss., doi:10.5194/amt-2016-385, 2016

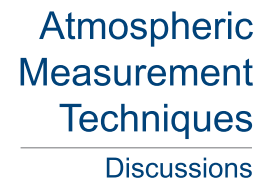

Manuscript under review for journal Atmos. Meas. Tech.

Published: 6 December 2016

(c) Author(s) 2016. CC-BY 3.0 License.

Discussions

(c) $\underset{\text { BY }}{(i)}$

amplitudes of daily curve (Figure 7) are similar for stations between $30^{\circ} \mathrm{S}$ and $30^{\circ} \mathrm{N}$. The tropical, warm temperate and a few dry stations situated within this latitude are characterized by daily amplitude higher than $4 \mathrm{~mm}$. A very good consistency can be noticed for diurnal amplitudes for polar and Alpine stations which unlike the annual amplitudes for stations in this climate zone, are at the level of $0.2-1 \mathrm{~mm}$, with a median of $0.4 \mathrm{~mm}$.

5 Figures 4 and 5 show that the phases of maxima of the annual and diurnal signals are well-correlated for both hemispheres. Amplitudes of daily curve are consistent for stations between $30^{\circ} \mathrm{S}$ and $30^{\circ} \mathrm{N}$ of latitude with one exception: station BELE (Belem, Brazil), which has an amplitude of daily changes as high as $11 \mathrm{~mm}$.

\subsection{Noise analysis of ZTD}

As shown in section 2, the ZTD residuals $\varepsilon_{Z T D}$ represent the misfit between real and modeled data. This misfit can be

10 resolved in several ways. The easiest one is an approach with a white noise process, which assumes, that the residuals are not correlated in time. In this case we adopt ordinary least-squares (LS) and estimate the covariance of fitted parameters as in equation (5). This approach is widely used in ZTD/IWV estimations in terms of climate applications (e.g., Jin et al., 2007; Flouzat et al., 2009; Morland et al., 2009; Ning et al., 2013; Bock et al., 2014). Nilsson and Elgered (2008) applied additional covariance as a function of time so as not to assume a pure white noise process. However, LSE was further used to

15 estimate the uncertainties of the determined parameters with the covariance matrix modified by these additional covariances. Combrink et al. (2007) proposed an $\operatorname{ARMA}(1,1)$ model to derive the most proper trend uncertainty which takes care of the real characteristics of IWV. Oladipo (1998) has analysed the power spectra of climatic time series. He emphasized that the first order autoregressive model is the preferred one for most cases analyzed. Other time series are best fitted by autoregressive models of second, third or fourth order. Mann and Lees (1996) pointed out that climatic time series have a

20 character of red noise in form of an autoregressive AR(1) process. Percival et al. (2004) modeled the climate time series of the North Pacific (NP) index as a first-order autoregressive process, namely AR(1). If ZTD time series are believed to resemble climatic variations that happen over years, then should these series also follow a low-order autoregressive model such as the climatic data do? When addressing this question, we propose to decide on an optimum model for the stochastic properties of ZTD time series using the Bayesian Information Criterion (BIC) (Schwarz, 1978) and Maximum Likelihood

25 Estimation (MLE) values. Both values are computed by fitting different noise models into the residuals. We start by applying a pure white noise model. In this case, the covariance of fitted parameters is estimated with equation (5) and the error of each individual ZTD sample is the only one that influences the results. Then, a combination of power-law (PL) and white (WH) noise process is implemented for which a covariance matrix of observations $\mathbf{C}$ is computed as:

$$
\mathbf{C}=a^{2} \cdot \mathbf{I}+b_{\kappa}^{2} \cdot \mathbf{J}_{\mathbf{\kappa}}
$$

30 where $a$ and $b$ are the amplitudes of the $\mathrm{WH}$ and PL noise processes, while $\mathbf{I}$ and $\mathbf{J}_{\mathbf{k}}$ are the covariance matrices of white and colored noise, respectively (Williams et al., 2003). We completed our analysis with autoregressive fractionally integrated moving average noise model (ARFIMA) of varying orders: $p, d$ and $q$ of AR, FI and MA, respectively. For a simple first order autoregressive noise model one gets an autocovariance of (Bos et al., 2013):

$$
\mathbf{C}\left(\varepsilon_{Z T D_{i}}, \varepsilon_{Z T D_{i+k}}\right)=\frac{\sigma^{2}}{1-\phi^{2}} \phi^{k}
$$

where $\sigma$ is a standard deviation of WH noise and $\phi$ is the coefficient of the AR(1) model. We applied WH, PL+WH and different autoregressive noise models using the Hector software package (Bos et al., 2012) and our decisions are based on the BIC and MLE values computed. Once the stochastic models were fitted to the residuals, $\varepsilon_{Z T D}$ presented in a double logarithmic scale. Figure 8 shows an example for five stations selected for different climate zones (MANA, Managua, Nicaragua; MAS1, Gran Canaria, Spain; AUCK, New Zealand; BJFS and SYOG, Syowa, Antarctica). Table 2 lists the trend 
Atmos. Meas. Tech. Discuss., doi:10.5194/amt-2016-385, 2016

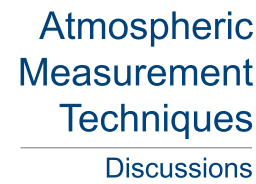

Manuscript under review for journal Atmos. Meas. Tech.

Published: 6 December 2016

(c) Author(s) 2016. CC-BY 3.0 License.

Discussions

with associated uncertainties for different noise models employed in this research. As can be seen from Power Spectral Densities presented in Figure 8, WH noise, which was widely used in previous studies to estimate trend uncertainties does not fit the ZTD residuals at all. The PL+WH noise model is the most proper one for use with GPS residual position time series and it somewhat fits both medium and higher frequencies of the PSD. However, it fails in the low frequency part,

5 leaving some of the power unexplained. This part can shift artificial correlation and increase the value of uncertainties of determined parameters. ARFIMA(1,0)+WH is quite similar to PL+WH for MANA and SYOG. When BJFS, MAS1 or AUCK are considered, ARFIMA(1,0)+WH matches the residuals better than the PL+WH noise model. The low-order autoregressive noise models are though the best for ZTD from any station analyzed. AR(1) is quite similar to the residuals, however, it does not explain all power below 30 (MANA), 10 (AUCK), 10 (MAS1), 100 (BJFS) and 1000 (SYOG) cpy. This might arise from the fact, that a simple dependence between each individual observation and its previous value that is assumed in $\mathrm{AR}(1)$ as in equation (1) is not what ZTD time series really follow. However, adding a pure white noise to AR(1) i.e. $\mathrm{AR}(1)+\mathrm{WH}$ makes the noise model suitably well fitted to the residuals, $\varepsilon_{Z T D}$. The adding of higher orders to the autoregressive model does not bring a clear and visible improvement when looking at the PSDs. However, we go further from the first to the fourth order of autoregressive model to examine if they will bring any improvement in a goodness of fit and in a trend error. All of them included white noise as a background which explained low and high frequencies in the residuals. We compared them for the noise models described above. The simplest white noise resulted for the five stations with trend values of: $-0.03 \pm 0.11$ (MANA), $1.29 \pm 0.08$ (AUCK), $0.32 \pm 0.05$ (MAS1), $0.49 \pm 0.07$ (BJFS) and $-0.31 \pm 0.03$ (SYOG) $\mathrm{mm} /$ year (Table 2). For the full results see the Table S2 in the supplementary information. All other examined stations had similar uncertainties of trend with few exceptions. One such exception is TWTF (Taoyuan City, Taiwan) with a trend equal to $-2.29 \pm 0.27 \mathrm{~mm} / \mathrm{yr}$. When a PL process was added to the $\mathrm{WH}$ noise $(\mathrm{PL}+\mathrm{WH})$, the trend uncertainty was enlarged by maximum of up to 105 times in comparison to the pure white process. A slight difference in the trend values is also noticed when comparing the results. First order autoregressive noise model, AR(1), increases the trend uncertainty by 4 times. However, looking at the PSD plot (Figure 8), AR(1) does not fit the residuals. When white noise is added to AR(1), $(\mathrm{AR}(1)+\mathrm{WH})$, the trend values remained almost the same, but its uncertainty increased 3 and 10 times, when compared to the

$25 \mathrm{AR}(1)$ and WH-only models, respectively. The fourth order autoregressive noise model in combination with a white noise process, AR(4)+WH, was chosen here as the optimal one for ZTD residuals based on the BIC and MLE values (Table 2). The trend uncertainties are inflated 8 times compared to the WH noise model. The ZTD residuals described by a fourth order autoregressive noise model in combination with white noise (AR(4)+WH) take the form of:

$$
\varepsilon_{Z T D_{i}}=\phi_{1} \cdot \varepsilon_{Z T D_{i-1}}+\phi_{2} \cdot \varepsilon_{Z T D_{i-2}}+\phi_{3} \cdot \varepsilon_{Z_{Z T D_{i-3}}}+\phi_{4} \cdot \varepsilon_{Z T D_{i-4}}+a_{t}
$$

where $\left[\phi_{1}, \ldots, \phi_{4}\right]$ are the coefficients of the autoregressive model, which describes how much the current value of ZTD depends on the four previous observations and $a_{t}$ represents white noise.

As AR(4)+WH noise is a combination of two independent noise models, we can describe a percentage contribution of each of them to the overall model. WH contributes ZTD residuals in $86 \%, 43 \%, 27 \%, 42 \%$ and $93 \%$ with standard deviations of 15.4, 9.2, 7.7, 11.4 and $8.5 \mathrm{~mm}$ for MANA, MAS1, AUCK, BJFS and SYOG, respectively. Likewise, the AR(4) model contributes in $14 \%, 57 \%, 73 \%, 58 \%$ and $7 \%$ with standard deviations of $6.3,10.7,12.7,13.5$ and 2.4 mm for MANA, MAS1, AUCK, BJFS and SYOG. We estimated the average noise level for all climate zones considered in Table 3. Table 3 shows that median amplitudes for AR(4)+WH are between 7.17 and $13.00 \mathrm{~mm}$ for white noise with the maximum for the tropical and the minimum for the polar and Alpine zone. The autoregressive part of this combination has amplitudes between 4.07 and $9.59 \mathrm{~mm}$ with a maximum for a tropical climate. The coefficients of the autoregressive process are the highest for the first term (AR(1)) with a maximum for the tropical zone.

Figure 9 and Table S2 in supplementary materials show values of trend when a pure white noise and autoregressive process of fourth order plus white noise are assumed. No regional dependencies can be observed. Six pairs of stations situated close 
Atmos. Meas. Tech. Discuss., doi:10.5194/amt-2016-385, 2016

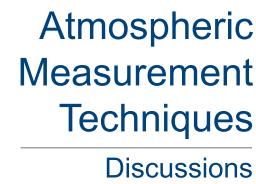

Manuscript under review for journal Atmos. Meas. Tech.

Published: 6 December 2016

(c) Author(s) 2016. CC-BY 3.0 License.

Discussions

to each other show a discrepancy in trend values. These are: ALRT-KMOR, GUAT-CHET, KOUR-MAPA, TWTF-TCMS, P211-TSKB, AUCK-MQZG. Four of these pairs show different time length (10 to 15 years). Trends estimated for stations situated in West coastline of North America, East coastline of South America, middle Europe, Indian Ocean and South Australia become insignificant when $\mathrm{AR}(4)+\mathrm{WH}$ is assumed. Trends for almost all stations in polar and Alpine (SH) become

5 insignificant when AR(4)+WH noise is assumed. Stations DAV1, DUM1, MCM4 are the only exceptions. These show a significant trend both for pure white and $\mathrm{AR}(4)+\mathrm{WH}$ process.

We estimate the ratios of the trend uncertainties derived with $\mathrm{AR}(4)+\mathrm{WH}\left(\sigma_{\mathrm{AR}(4)+\mathrm{WH}}\right)$ and $\mathrm{WH}$-only $\left(\sigma_{\mathrm{WH}}\right)$ noise models as:

ratio $=\frac{\sigma_{A R(4)+W H}}{\sigma_{W H}}$

This ratio ranges between 1 and 12 for the set of analyzed stations (Figure 10 and Table S2 in supplementary materials). No

10 climate classification dependence is apparent here. The trend itself may become insignificant when the noise model was changed from white into AR(4)+WH as e.g. for ALGO, ALIC, ALRT, HRAO, TOW2, etc. This suggests that a trend uncertainty derived from ZTD time series can be interpreted in terms of climate change only if the stochastic properties are fully accounted for by a proper noise model, which obviously is not a white noise only model.

\section{Discussion}

15 Homogenously re-processed time series within our repro2 solution delivered consistent time series with no artificial jumps due to changes in models (as was shown by Steigenberger et al. (2007)). Ning et al. (2016) applied a PMTred test (penalized maximal $t$ test modified to account for first-order autoregressive noise in time series) to detect breaks in differences between IWV estimated with ERA-Interim model and GPS-retrieved estimates. They corrected the detected breaks even if the epoch was not reported before in a log-file of station. Homogenisation of ZTD data in this study was performed by manual detection of breaks, cross-validation with stations' log-files and the use of earthquake files and the discontinuity file from ITRF2008. It brought an improvement in ZTD standard deviation and trend estimations. Ning et al. (2016) found a maximum difference in trend between homogenized and not-homogenized IWV data of $-2.28 \mathrm{~kg} / \mathrm{m}^{2}$ for KELY station (Kangerlussuaq, Greenland). In our research, KELY was affected by 4 offsets. However, a most dramatic change in trend of $3.7 \mathrm{~mm} / \mathrm{decade}$ for data before and after homogenization was found in this study for station POHN with 4 offsets being applied. One can be misled by trend estimates if offsets are not removed properly or neglected. Besides, undetected or unmodeled discontinuities may also introduce a component of random-walk noise. Homogenization should be considered for a proper analysis of ZTD time series, in particular for climate studies.

The main variability of ZTD comes from ZWD, as was shown in this study in a pre-analysis and also stated earlier by Jin et al. (2007). Temporal variations determined here showed a good agreement in amplitude and phase for annual curves for both

30 Northern and Southern Hemisphere. The maxima of annual sine fall between July and August for the Northern Hemisphere, while between January and February for the Southern Hemisphere. Both periods fall in the summer for the corresponding Hemisphere. Annual amplitudes vary between 10 and $150 \mathrm{~mm}$. The largest were found for the tropical zone and oceanic coasts with a few large amplitudes for east Asia, Japan and east coast of North America. The polar and Alpine zone is characterized by almost flat annual sine curve, which is due to lack of differences between summer and winter. The maximum of the semi-annual cycle falls in January for the Northern Hemisphere and are uncorrelated in phase for the Southern Hemisphere. Similar results were reported before by Jin et al. (2007).

The largest amplitudes of daily oscillations are found for stations in the tropical zone, while those in both polar and Alpine zones are almost flat. Day-to-day variations arise from changes in ambient temperature and pressure. Homogenous daily changes were found here for a set of European stations with a peak of daily oscillation around 18 hours. The same was reported before by Jin et al. (2009) with IGS GPS observations and data from Comprehensive Ocean-Atmosphere Data Set 
Atmos. Meas. Tech. Discuss., doi:10.5194/amt-2016-385, 2016

Manuscript under review for journal Atmos. Meas. Tech.

Published: 6 December 2016

(c) Author(s) 2016. CC-BY 3.0 License.

$\begin{array}{r}\text { Atmospheric } \\ \text { Measurement } \\ \text { Techniques } \\ \hline \text { Discussions }\end{array}$

(COADS) surface pressure. Similar results were also reported before by Ning et al. (2013). However, few inconsistences were noticed. A diurnal peak for station VILL (Villanueva, Spain) falls at 1 a.m. in this study, while those happened at 6 p.m. in Ning et al. (2013). However, the diurnal amplitude for VILL is insignificant, i.e. smaller than its error. Diurnal peaks for other stations from Europe agree to within 2 hours with those shown in Ning et al. (2013).

5 The frequency spectra of the ZTD estimates and the GPS position time series follow a well-defined fractal distribution, i.e. amplitude and frequency are related by means of a power-law. However, their spectral indices differ, i.e. GPS position time series stochastic character is not transferred to the power property of the ZTD time series. This shows of the good separation between position and troposphere estimates with the latter following the properties of other climate series.

Combrink et al. (2007) showed that an ARMA(1,1) noise model represents residuals of IWV data better than a pure white

10 noise model. The same was reported in this study for ARMA(1,1)+WH. However, we added a further step and analyzed higher orders of an autoregressive process (up to $4^{\text {th }}$, higher orders are computationally intensive). The AR(4)+WH noise model is found to be optimal for ZTD time series based on the BIC and MLE values. White noise, which is widely assumed for ZTD time series, does not fit ZTD residuals at all. PL+WH noise, which is commonly used for GPS position time series, fails for the low frequencies and can bring artificial correlations within. The AR(1) model that is the most often used for any

15 of climate time series (e.g. Percival et al., 2004) fits the ZTD residuals as well, but only if white noise was added. Uncorrelated white noise explains low and high frequencies of data, while the autoregressive model is optimal for the medium frequencies. We added another three orders to the autoregressive part of the model and found that, the fourth order is the best noise model with respect to the BIC and MLE metrics.

Combrink et al. (2007) showed that 1-sigma uncertainties of the PWV trend for station HRAO (Hartbeespoort, RSA)

20 significantly decreased when: 1) noise model is being changed from $\operatorname{ARMA}(1,1)$ to white noise and 2) number of data used in the analysis increased. In this analysis, we used 17 years of data from station HRAO and obtained a 1-sigma uncertainty of ZTD trend at the level of $0.07 \mathrm{~mm} / \mathrm{yr}$ for pure white noise and at the level of $0.52 \mathrm{~mm} / \mathrm{yr}$ for AR(4)+WH. When shorter time series is used, the error will be apparently higher.

Jin et al. (2007) accounted for trend values in 2-hour resolution ZTD series for a set of 150 IGS stations. They showed

25 significant up- and downward trends with almost half of them higher than $2 \mathrm{~mm} / \mathrm{yr}$ for Northern and Southern Hemisphere. They showed that almost all stations for Northern Hemisphere have a positive trend, while those in Southern Hemisphere are directed downward. However, their analysis was performed for a white-noise-only process. Our analysis of 21-years ZTD series shows few similarities to what was shown by Jin et al. (2007). The number of 21 stations have similar (up- or downward) trend. These are: KOKB, NEAH, LPAZ, GUAT, ALRT, BRFT, NKLG, VILL, MATE, POTS, LAMA, NYAL, RAMO, ARTU, NRIL, IISC, BILI, KARR, PERT, DAV1, KERG.

We estimated the trend uncertainties with the $\mathrm{AR}(4)+\mathrm{WH}$ noise model. This showed that to date, trend uncertainties were underestimated of up to 12 times for some stations. When the AR(4)+WH noise model was assumed some trends became insignificant, which means that they should not have been interpreted in terms of climate change. When a pure white noise is assumed, only 11 from a set of selected 120 stations have insignificant trend within 1-sigma error bar. These are: MANA, FAIR, SSA1, HOFN, P211, MDO1, MCM4, KIR0, VNDP, WILL and WSRT. Having changed the noise model from WH into AR(4)+WH, the number of only 64 trends from 120 stations is significant. Trends estimated for stations MANA, FAIR, MDO1, MCM4, KIR0, SSA1, HOFN, VNDP, WILL and WSRT are insignificant for both white and autoregressive of fourth order plus white. Few estimates of trends, which we found in this study as insignificant for AR(4)+WH, were shown in Jin et al. (2007) with a pure white noise. These trends were derived for: NEAH, NANO, WILL, QUIN, VNDP, MDO1, ALGO, HOFN, LAMA, KIR0, WSRT, HRAO, DGAR, KERG, CAS1, MCM4, MAC1, HOB2, ALIC, NTUS and TWTF. Also, few stations all located at or close to Antarctica regions: MCM4, CAS1, MAC1, SYOG and PALM, used before by Thomas et al. (2011), have insignificant trends, when AR(4)+WH is employed. 
Atmos. Meas. Tech. Discuss., doi:10.5194/amt-2016-385, 2016

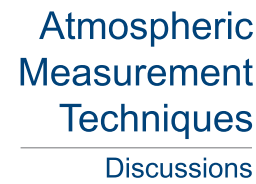

Manuscript under review for journal Atmos. Meas. Tech.

Published: 6 December 2016

(c) Author(s) 2016. CC-BY 3.0 License.

Discussions

(c) $\underset{\text { BY }}{(i)}$

\section{Conclusions}

A data set of homogenous ZTD data could be used for assimilation into climate models similarly to their assimilation into numerical weather prediction models. This study describes the deterministic and stochastic characteristics of ZTD time series for a selection of 120 stations from the re-analysis of global tracking stations from more than 700 stations around the world

5 for 1995 to 2015. Our TIGA second re-processing (repro2) at the University of Luxembourg solution follow the recent model developments and the latest International Earth Rotation and Reference Systems Service (IERS) 2010 conventions. This re-processing guarantees consistent ZTD over the complete time span and only time series longer than 6 years have been considered. Similar studies have shown that the re-processed ZTD time series and the derived IWV time series can be employed for the evaluation of re-analysis models and potentially also for climate models. Since ZTD is interpreted as a change in climate, it needs to be properly analyzed before we decide on any climate change studies. Often ZTD time series are affected by discontinuities of various sources that include hardware changes, earthquake and unknown sources. Discontinuities or offsets in the ZTD time series degrade the accuracy of the magnitude of the estimated trend if they are not identified and modeled. In this study, we have semi-automatically (partly manually) identified a number of 2500 discontinuities in the position time series for the 750 stations. When these were applied to the ZTD time series, the most dramatic change in trend of $3.7 \mathrm{~mm} /$ decade was found for station POHN. Stations WES2, TSKB and TWTF are characterized by the largest number of offsets applied.

We have then set up a priori significant frequencies that appear in ZTD time series, i.e. annual, semi-annual, a third of a year, a quarter, daily and sub-daily. These periodic signals if mis-modelled will bring additional correlation into the stochastic component of the underlying noise of the ZTD residuals. Furthermore, it can artificially remove some of the real power, although this is quite insignificant. The residual times series will vary with every change in deterministic model. We subdivided the GPS stations from our repro2 solution into five different climate zones according to the Köppen-Geiger climate classification. A total of 120 GPS stations were used for this study from all the five climates zones distributed globally. We examined on all significant periodicities after adjusting the data for discontinuities. The annual peak is the most powerful one for all stations included in the study. Its amplitude ranges between 10 and $150 \mathrm{~mm}$ being dependent on the climate zone the station is located in. The smallest amplitudes were found for the polar and Alpine zone, but only for stations situated in Southern Hemisphere. The amplitudes for the polar and Alpine zone of the Northern Hemisphere are almost as large as for the continental zone. The annual peak is followed by the semi-annual oscillation, of which the power is half as large as for the annual peak for $70 \%$ of the analyzed stations. We found very good consistency in phase shifts for the semi-annual oscillation. These fall into January/February for almost all stations situated in the Northern Hemisphere with significant amplitude, when compared to those from the Southern Hemisphere. The phase shifts for stations in the Southern Hemisphere are less consistent, possibly due to the more varied ocean-land distribution. However, five of them, situated in Antarctica, have consistent peaks in early January. The amplitudes of daily curve fall between 0 and $12 \mathrm{~mm}$. The greatest were found for the dry zone while the continental and the polar and Alpine zones are characterized by the smallest day-to-day changes.

Up until now, the stochastic component of the ZTD residuals has widely been modeled as a white noise only process i.e. with no time correlation between observations. In that case, little impact on the parameters (including trend) and their uncertainties of the deterministic component is evident. In this study, we proposed an innovative approach of autoregressive process plus white noise $(\mathrm{AR}(4)+\mathrm{WH})$ to investigate the stochastic component of the ZTD residual time series. We used few different assumptions of noise model and showed, based on the BIC and MLE, that an autoregressive process of fourth order appears to be the most appropriate model for the noise characteristic of the ZTD residual time series. This is in agreement with other results from climatologists who analyzed different climatic time series such as temperature, pressure and humidity with all follow an autoregressive noise model. The residual ZTD time series show a temporal correlation that appears to be explained by an autoregressive process of fourth order combined with white noise irrespective of the climate zone considered. The tropical zone is characterized by the largest amplitude of autoregressive noise $(9.59 \mathrm{~mm})$ compared to other 
Atmos. Meas. Tech. Discuss., doi:10.5194/amt-2016-385, 2016

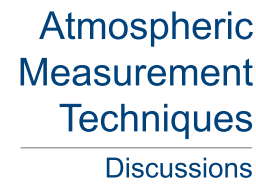

Manuscript under review for journal Atmos. Meas. Tech.

Published: 6 December 2016

(c) Author(s) 2016. CC-BY 3.0 License.

Discussions

zones and the largest median of amplitudes of white noise $(13.68 \mathrm{~mm})$. All climate zones are characterized by similar

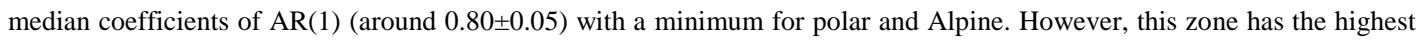
coefficients of $\mathrm{AR}(2)(0.27 \pm 0.01)$ and $\mathrm{AR}(3)(0.11 \pm 0.01)$, clearly being different from the other zones considered.

We show that 56 of 120 trends from selected stations in this study became insignificant when the optimum noise model was

5 employed. We compare this to 109 significant trends when the WH noise only is assumed. Some of these stations were also analyzed in previous studies in terms of long-term changes. Therefore, we would recommend that a combination of autoregressive process with white noise has to be taken into account when aiming at the estimation of secular trends from any tropospheric (ZTD or IWV) series. If a proper stochastic model is not employed, one will obtain results that cannot be interpreted in terms of climate change as the uncertainty of the ZTD residuals may be underestimated by a factor of 3 to 12 compared to the white noise only assumption.

Acknowledgments. Anna Klos was supported by COST Action ES1206 GNSS4SWEC (gnss4swec.knmi.nl) during her stay at the University of Luxembourg. Janusz Bogusz is supported by the Polish National Science Centre grant no. UMO2016/21/B/ST10/02353. Addisu Hunegnaw is funded by the University of Luxembourg IPRs GSCG and SGSL. Kibrom Ebuy Abraha is funded by the Fonds National de la Recherche, Luxembourg (Reference No. 6835562). The computational resources used in this study were partly provided by the High Performance Computing Facility at the University of Luxembourg (ULHPC). We acknowledge IGS/TIGA for providing the GNSS data and CODE for their products.

\section{References}

Beaulieu, C., Seidou, O., Ouarda, T. B. M. J., Zhang, X., Boulet, G. and Yagouti, A.: Intercomparison of homogenization techniques for precipitation data. Water Resour. Res., 44, W02425, doi:10.1029/2006WR005615, 2008.

Bevis, M., Businger, S., Herring, T. A., Rocken, C., Anthes, R. A. and Ware, R. H.: GPS meteorology: Remote sensing of atmospheric water vapor using the global positioning system, J. Geophys. Res., 97(D14), 801, doi:10.1029/92JD01517, 1992.

Bock, O., Bouin, M. N., Walpersdorf, A., Lafore, J. P., Janicot, S., Guichard, F. and Agusti-Panareda, A.: Comparison of groundbased GPS precipitable water vapour to independent observations and NWP model reanalysis over Africa, Q. J. Roy. Meteor. Soc., 113:2011-2027, doi: 10.1002/qj.185, 2007.

Bock, O., Bosser, P., Pacione, R., Nuret, M., Fourri, N. and Parracho, A.: A high quality reprocessed ground-based GPS dataset for atmospheric process studies, radiosonde and model evaluation, and reanalysis of HyMeX Special Observing Period, Q. J. Roy. Meteor. Soc., doi:10.1002/qj.2701, 2016.

Bock, O., Willis, P., Wang, J. and Mears, C.: A high-quality, homogenized, global, long-term (1993-2008) DORIS precipitable water data set for climate monitoring and model verification, J. Geophys. Res., 119(12), doi:10.1002/2013jd021124, 2014

Böhm, J., Werl, B. and Schuh, H.: Troposphere mapping functions for GPS and very long baseline interferometry from european centre for medium-range weather forecasts operational analysis data, J. Geophys. Res., 111(B0), doi: 10.109/005JB00369, 2006.

35 Bos, M., Williams, S., Araujo, I. and Bastos, L.: The effect of temporal correlated noise on the sea level rate and acceleration uncertainty, Geophys. J. Int., 196(3), doi:10.1093/gji/ggt481, 2013.

Bos, M.S., Fernandes, R. M. S., Williams, S. D. P. and Bastos, L.: Fast error analysis of continuous GNSS observations with missing data, J. Geod., 87(4), doi:10.1007/s00190-012-0605-0, 2012. 
Atmos. Meas. Tech. Discuss., doi:10.5194/amt-2016-385, 2016

Manuscript under review for journal Atmos. Meas. Tech.

Published: 6 December 2016

(c) Author(s) 2016. CC-BY 3.0 License.

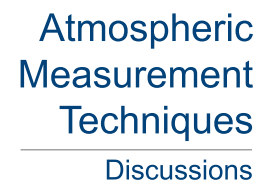

Brenot, H., Ducrocq, V., Walpersdorf, A., Champollion, C. and Caumont, O.: GPS zenith delay sensitivity evaluated from high-resolution numerical weather prediction simulations of the 89 September 2002 flash flood over southeastern France, J. Geophys. Res., 111(D15), doi:10.1029/2004JD005726, 2006.

Chen, G. and Herring, T. A.: Effects of atmospheric azimuthal asymmetry on the analysis of space geodetic data, J. Geophys. Res., 102(B9):20,489-20,502, doi:10.1029/97JB01739, 1997.

Combrink, A. Z., Bos, M. S., Fernandes, R. M. S., Combrinck, W. L. and Merry, C. L.: On the importance of proper noise modelling for long-term precipitable water vapour trend estimations, SAFR J. Geol., 2007,110, pp. 211-218, doi: 10.2113/gssajg.110.2-3.211, 2007.

Dach, R., Lutz, S., Walser, P. and Fridez, P.: Bernese GNSS Software Version 5.2, 2015.

10 Dach, R., Stefan, S., Arnold, D., Orliac, E., Prange, L., Suśnik, A., Villiger, A. and Jäggi, A.: CODE final product series for the IGS, Published by Astronomical Institute, University of Bern, doi: 10.7892/boris.75876, 2016.

Davis, J. L., Herring, T. A., Shapiro, I. I., Rogers, A. E. and Elgered, G.: Geodesy by radio interferometry: Effects of atmospheric modeling errors on estimates of baseline length. Radio. Sci., 20(6), doi:10.1007/s00190-011-0491-x, 1985.

Dousa, J.: The impact of errors in predicted GPS orbits on zenith troposphere delay estimation, GPS Solut., 14(3), 229-239, doi: 10.1007/s10291-009-0138-z, 2010.

Dow, J. M., Neilan, R. E. and Rizos, C.: The International GNSS Service in a changing landscape of Global Navigation Satellite Systems, J. Geod., 83, doi:10.1007/s00190-008-0300-3, 2009.

Flouzat, M., Bettinelli, P., Willis, P., Avouac, J. P., Heritier, T. and Gautam, U.: Investigating tropospheric effects and seasonal position variations in GPS and DORIS timeseries from the Nepal Himalaya, Geophys. J. Int., 178(3):12461259, doi:10.1111/j.1365-246X.2009.04252.x, 2009.

Fu, Y., Argus, D. F., Freymueller, J. T. and Heflin, M. B.: Horizontal motion in elastic response to seasonal loading of rain water in the amazon basin and monsoon water in Southeast Asia observed by GPS and inferred from GRACE, J. Geophys. Res., 40(23), doi:10.1002/2013g1058093, 2013.

Gazeaux, J., Flaounas, E., Naveau, P. and Hannart, A.: Inferring change points and non-linear trends in multivariate time series: Application to west African monsoon onset timings estimation, J. Geophys. Res., 116(D5), doi:10.1029/2010JD014723, 2011.

Gazeaux, J., Williams, S., King, M., Bos, M., Dach, R., Deo, M., Moore, A. W., Ostini, L., Petrie, E., Roggero, M., Teferle, F. N., Olivares, G. and Webb F.H.: Detecting offsets in GPS time series: First results from the detection of offsets in GPS experiment, J. Geophys. Res., 118(5), doi:10.1002/jgrb.50152, 2013.

Griffiths, J. and Ray, J.: Impacts of GNSS position offsets on global frame stability, Geophys. J. Int., 204(1), doi:10.1093/gji/ggv455, 2015.

Guerova, G., Jones, J., Dousa, J., Dick, G., de Haan, S., Pottiaux, E., Bock, O., Pacione, R., Elgered, G., Vedel, H. and Bender, M.: Review of the state-of-the-art and future prospects of the ground-based GNSS meteorology in Europe, Atmos. Meas. Tech. Discuss., 2016, 1-34, doi:10.5194/amt-2016-125, 2016.

Guerova, G., Bettems, J. M., Brockmann, E. and Matzler, C.: Assimilation of the GPS-derived integrated water vapour (IWV) in the MeteoSwiss numerical weather prediction model - a first experiment, Phys. Chem. Earth, 29, 177-186, doi: 110.1016/j.pce.2004.1001.1009, 2004.

Hagemann, S., Bengtsson, L. and Gendt, G.: On the determination of atmospheric water vapor from GPS measurements, J. Geophys. Res., 108(D21), 4678, doi:10.1029/2002JD003235, 2003.

Held, I., and Soden, B.: Water vapor feedback and global warming, Annual Review of Energy and the Environment, 25:445475, doi:10.1146/annurev.energy.25.1.441, 2000. 
Atmos. Meas. Tech. Discuss., doi:10.5194/amt-2016-385, 2016

Manuscript under review for journal Atmos. Meas. Tech.

Published: 6 December 2016

(c) Author(s) 2016. CC-BY 3.0 License.

Hunegnaw, A., Teferle, F. N., Bingley, R., Hansen, D.: Status of TIGA Activities at the British Isles Continuous GNSS Facility and the University of Luxembourg, C. Rizos, P. Willis (eds.), International Association of Geodesy Symposia, 143:617- 623,doi:10.1007/1345-2015-77, 2016.

Jin, S., Park, J. U., Cho, J.-Ch. and Park, P. H.: Seasonal variability of GPS-derived zenith tropospheric delay (1994-2006) and climate implications, J. Geophys. Res., 112, D09110, doi:10.1029/2006JD007772, 2007.

Jin, S., Luo, O. F. and Gleason, S.: Characterization of diurnal cycles in ZTD from a decade of global GPS observations, J. Geod., 83(6), doi:10.1007/s00190-008-0264-3, 2008.

Johnson, H. and Agnew, D.: Monument motion and measurements of crustal velocities. Geophys. Res. Lett., 22:2905-2908, 1995.

10 Khodabandeh, A., Amiri-Simkooei, A. R. and Sharifi, M. A.: GPS position time series analysis based on asymptotic normality of m-estimation, J. Geod., 86(1), doi:10.1007/s00190-011-0489-4, 2011.

Klos, A., Bogusz, J., Figurski, M. and Gruszczynski, M.: Error analysis for European IGS stations, Stud. Geophys. Geod., 60:17-34, doi: 10.1007/s11200-015-0828-7, 2016.

Kroszczynski, K.: Angular Distributions of Discrete Mesoscale Mapping Functions, Acta Geophysica vol. 63, no. 4 (2015), pp. 1126 - 1149, doi: 10.1515/acgeo-2015-0035, 2015.

Labbouz, L., Van-Baelen, J., Tridon, F., Reverdy, M., Hagen, M., Bender, M., Dick, G., Gorgas, T. and Planche, C.: Precipitation on the lee side of the vosges mountains: Multi-instrumental study of one case from the cops campaign, Meteorol. Z., 22(4):413-432, doi:10.1127/0941-2948/2013/0413, 2013.

Langbein, J. and Johnson, H.: Correlated errors in geodetic time series: Implications for time-dependent deformation, J. Geophys. Res., 102(B1):591, doi:10.1029/96jb02945, 1997.

Larson, K. M., Freymueller, J. T. and Philipsen, S.: Global plate velocities from the Global Positioning System, J. Geophys. Res., 102(B5), doi:10.1029/97JB00514, 1997.

Mahfouf, J. F., Ahmed, F., Moll, F., Patrick, M. and Teferle, F. N.: Assimilation of zenith total delays in the AROME France convective scale model: a recent assessment, Tellus A., 67(0), doi: 10.3402/tellusa.v67.26106, 2015.

Mann, M. and Lees, J.: Robust estimation of background noise and signal detection in climatic time series, Climatic Change., 33, 409-445, 1996.

Mao, A., Harrison, C. G. A., Dixon, T. H.: Noise in GPS coordinate time series, J. Geophys. Res., 104(B2), 2797, doi:10.1029/1998jb900033, 1999.

Marini, J. W.: Correction of satellite tracking data for an arbitrary tropospheric profile, Radio. Sci., 36:223-231, 1972.

30 Matyasovszky, I.: Spectral analysis of unevenly spaced climatological time series, Theor. Appl. Climatol. 111(3-4):371-378, doi:10.1007/s00704-012-0669-z, 2012.

Morland, J., Coen, M., Hocke, K., Jeannet, P. and Atzler, C.: Tropospheric water vapour above Switzerland over the last 12 years, Atmos. Chem. Phys., 9, 59755988, doi:10.5194/acp-9-5975-2009, 2009.

Nilsson, T. and Elgered, G.: Long-term trends in the atmospheric water vapor content estimated from ground-based GPS data, J. Geophys. Res., 113(D19), doi:10.1029/2008jd010110, 2008.

Ning, T., Elgered, G., Willen, U. and Johansson, J. M.: Evaluation of the atmospheric water vapor content in a regional climate model using ground-based GPS measurements, J. Geophys. Res.,118(2):329-339, doi:10.1029/2012jd018053, 2013.

Ning, T., Wickert, J., Deng, Z., Heise, S., Dick, G., Vey, S. and Schöne, T.: Homogenized time series of the atmospheric water vapor content obtained from the GNSS reprocessed data, J. Climate, doi: 10.1175/JCLI-D-15-0158.1, 2016.

Oladipo, E.O.: Spectral analysis of climatological time series: On the performance of periodogram, non-integer and maximum entropy methods, Theor. Appl. Climatol., 39, 40-53, 1998. 
Atmos. Meas. Tech. Discuss., doi:10.5194/amt-2016-385, 2016

Manuscript under review for journal Atmos. Meas. Tech.

Published: 6 December 2016

(c) Author(s) 2016. CC-BY 3.0 License.

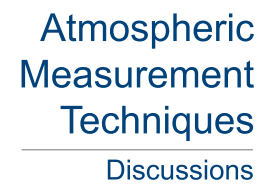

Ostini, L.: Analysis and quality assessment of GNSS derived parameter time series, Ph.D. thesis, Philosophisch naturwissenschaftlichen Fakultt of the University of Bern, 2012.

Peel, M. C., Finlayson, B. L. and Mcmahon, T. A.: Updated world map of the Köppen-Geiger climate classification, Hydrology and Earth System Sciences Discussions, European Geosciences Union, 2007, 4 (2), pp.439-473, 2007.

5 Percival, D. B., Overland, J. E. and Mofjeld, H. O.: Modeling North Pacific Climate Time Series. Chapter in: Time Series Analysis and Applications to Geophysical Systems, vol 139. Springer, 2007.

Petit, G. and Luzum, B.: IERS Technical Note no 36., IERS Convention Centre. Tech. rep., Frankfurt am Main: Verlag des Bundesamts fur Kartographie und Geodäsie, 2010.

Rebischung P., Griffiths, J., Ray, J., Schmid, R., Collilieux, X. and Garayt, B.: IGS08: the IGS realization of ITRF2008, GPS Solut., 16:483494 doi:10.1007/s10291-011-0248-2, 2012.

Rohm, W., Zhang, K., Bosy, J.: Limited constraint, robust Kalman filtering for GNSS troposphere tomography, Atmos. Meas. Tech. 7(5):1475-1486 - May 2014, doi: 10.5194/amt-7-1475-2014, 2014.

Santamaria-Gómez, A., Bouin, M. N., Collilieux, X. and Wöppelmann, G.: Correlated errors in GPS position time series: Implications for velocity estimates, J. Geophys. Res., 116(B1), doi:10.1029/2010jb007701, 2011.

15 Schwarz, G.: Estimating the dimension of a model. Annals of Statistics 6, 461-464, 1978.

Sella, G. F., Stein, S., Dixon, T. H., Craymer, M., James, T. S., Mazzotti, S. and Dokka, R. K.: Observation of glacial isostatic adjustment in stable North America with GPS, Geophys. Res. Lett., 34(2), doi:10.1029/2006g1027081, 2007.

Sguerso, D., Labbouz, L. and Walpersdorf, A.: 14 years of GPS tropospheric delays in the French-Italian border region: a data base for meteorological and climatological analyses, ISPRS Archives, XL-5/W3:5975-5988, 2013.

20 Simmons, A. J. and Gibson, J. K.: The ERA40 Project plan, ECMWF Rep. Ser. 1, 62 pp., Eur. Cent. for Med.-Range Weather Forecasts, Reading, U.K, 2000.

Soden, B. J. and Held, I. M.: An assessment of climate feedbacks in coupled ocean atmosphere models. J. Clim., 19, pp. 3354-3360, doi: 10.1175/JCLI3799.1, 2008.

Sowel, F.: Maximum likelihood estimation of stationary univariate fractionally integrated time series models. J. Econom., $53: 165-188,1992$.

Steigenberger, P., Tesmer, V., Krügel, M., Thaller, D., Schmid, R., Vey, S. and Rothacher, M.: Comparisons of homogeneously reprocessed GPS and VLBI long time-series of troposhere zenith delays and gradients, J. Geod., 81, 6-8, 503-514, doi: 10.1007/s00190-006-0124-y, 2007.

Teferle, F. N., Bingley, R. M., Orliac, E. J., Williams, S. D. P., Woodworth, P. L., McLaughlin, D., Baker, T. F., Shennan, I., Milne, G. A., Bradley, S. L. and Hansen, D. N.: Crustal motions in great Britain: evidence from continuous GPS, absolute gravity and Holocene sea-level data, Geophys. J. Int., 178:23-46, doi:10.1111/j.1365-246X.2009.04185.x, 2009.

Teferle, F. N., Williams, S. D. P., Kierulf, H. P., Bingley, R. M. and Plag, H. P.: A continuous GPS coordinate time series analysis strategy for high-accuracy vertical land movements, Phys. Chem. Earth, 33(3-4):205-216, doi:10.1016/j.pce.2006.11.002, 2008.

Thomas, I. D., King, M. A., Clarke, P. J. and Penna, N. T.: Precipitable water vapor estimates from homogeneously reprocessed GPS data: An intertechnique comparison in Antarctica, J. Geophys. Res., 116(D4),doi:10.1029/2010JD013889, 2011.

Tregoning, P. and Herring, T. A.: Impact of a priori zenith hydrostatic delay errors on GPS estimates of station heights and zenith total delays, Geophys. Res. Lett., 33(L23303), doi:10.1029/2006GL027706, 2006.

40 Trenberth, K. E., Dai, A., Ramsmussen, R. M. and Parsons, D. B.: The changing character of precipitation, Bull Amer. Meteor. Soc., 84(9),doi:10.117/BAMS-84-9-1205, 2003.

van Dam, T. M., Blewitt, G. and Heflin, M. B.: Atmospheric pressure loading effects on Global Positioning System coordinate determinations, J. Geophys. Res., 99, 23,93923,950,doi:10.1029/94JB02122, 1994. 
Atmos. Meas. Tech. Discuss., doi:10.5194/amt-2016-385, 2016

Manuscript under review for journal Atmos. Meas. Tech.

Published: 6 December 2016

(c) Author(s) 2016. CC-BY 3.0 License.

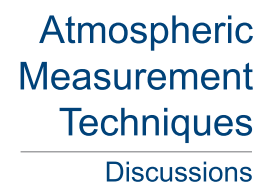

(c) (i)

Vey, S., Dietrich, R., Fritsche, M., Rulke, A., Steigenberger, P. and Rothacher, M.: On the homogeneity and interpretation of precipitable water time series derived from global GPS observations, J. Geophys. Res., 114(D10), doi:10.1029/2008JD010415, 2009.

Walpersdorf, A., Bouin, M. N., Bock, O. and Doerflinger, E.: Assessment of GPS data for meteorological applications over

5 Africa: Study of error sources and analysis of positioning accuracy, J. Atmos. Sol-Terr. Phy., 69:1312-1330, doi: 10.1016/j.jastp.2007.04.008, 2007.

Wang, X., Zhang, K., Wu, S., Fan, S. and Cheng, Y.: Water vapor-weighted mean temperature and its impact on the determination of precipitable water vapor and its linear trend, J. Geophys. Res. Atmos., 121(2), 833-852, doi: 10.1002/2015JD024181, 2016.

10 Wilgan, K., Hurter, F., Geiger, A., Rohm, W. and Bosy, J.: Tropospheric refractivity and zenith path delays from leastsquares collocation of meteorological and GNSS data, J. Geod., doi: 10.1007/s00190-016-0942-5, 2016.

Williams, S. D. P.: Offsets in Global Positioning System Time Series, J. Geophys. Res., 108(B6), 2310; doi: 2310.1029/2002JB002156, 2003a.

Williams, S. D. P.: The effect of coloured noise on the uncertainties of rates estimated from geodetic time series, J. Geod., 76(9-10):483-494,doi:10.1007/s00190-002-0283-4, 2003b.

Williams, S. D. P.: Error analysis of continuous GPS position time series, J. Geophys. Res., 109(B3), doi:10.1029/2003jb002741.

Wöppelmann G., Letetrel, C., Santamaria-Gómez, A., Bouin, M., Collilieux, X., Altamimi, Z., Williams, S. and Miguez M., B.: Rates of sea-level change over the past century in a geocentric reference frame, Geophys. Res. Lett., 36, doi:10.1029/2009GL038720, 2009.

Wu, X., Heflin, M. B., Ivins, E. R., Argus, D. F. and Webb, F. H.: Large-scale global surface mass variations inferred from GPS measurements of load-induced deformation, Geophys. Res. Lett., 30(14), doi:10.1029/2003GL017546, 2003.

Yan, X., Ducrocq, V., Poli, P., Hakam, M., Jaubert, G. and Walpersdorf, A.: Impact of GPS zenith delay assimilation on convective-scale prediction of Mediterranean heavy rainfall, J. Geophys. Res. 114(D3), doi:10.1029/2008JD011036, 2009.

Yuan, L. L., Anthes, R. A., Ware, R. H., Rocken, C., Bonner, W. D., Bevis, M. G. and Businger, S.: Sensing climate change using the Global Positioning System, J. Geophys. Res., 98(14),doi:10.1029/93JD00948, 1993. 
Atmos. Meas. Tech. Discuss., doi:10.5194/amt-2016-385, 2016

Manuscript under review for journal Atmos. Meas. Tech.

Published: 6 December 2016

(c) Author(s) 2016. CC-BY 3.0 License.

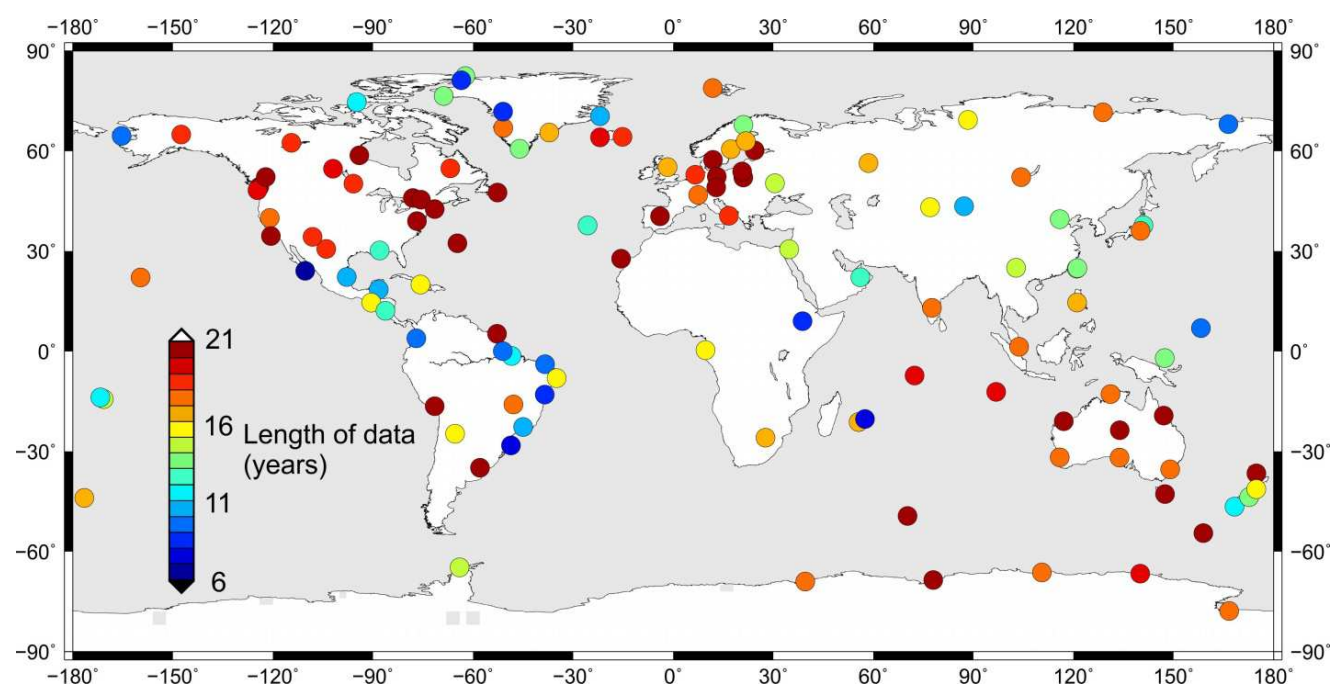

Figure 1: 120 selected global stations from the reprocessed TIGA solution. The selection is based on the time length of the ZTD time series and their quality. We have only selected those sites having a minimum length of 6 years.

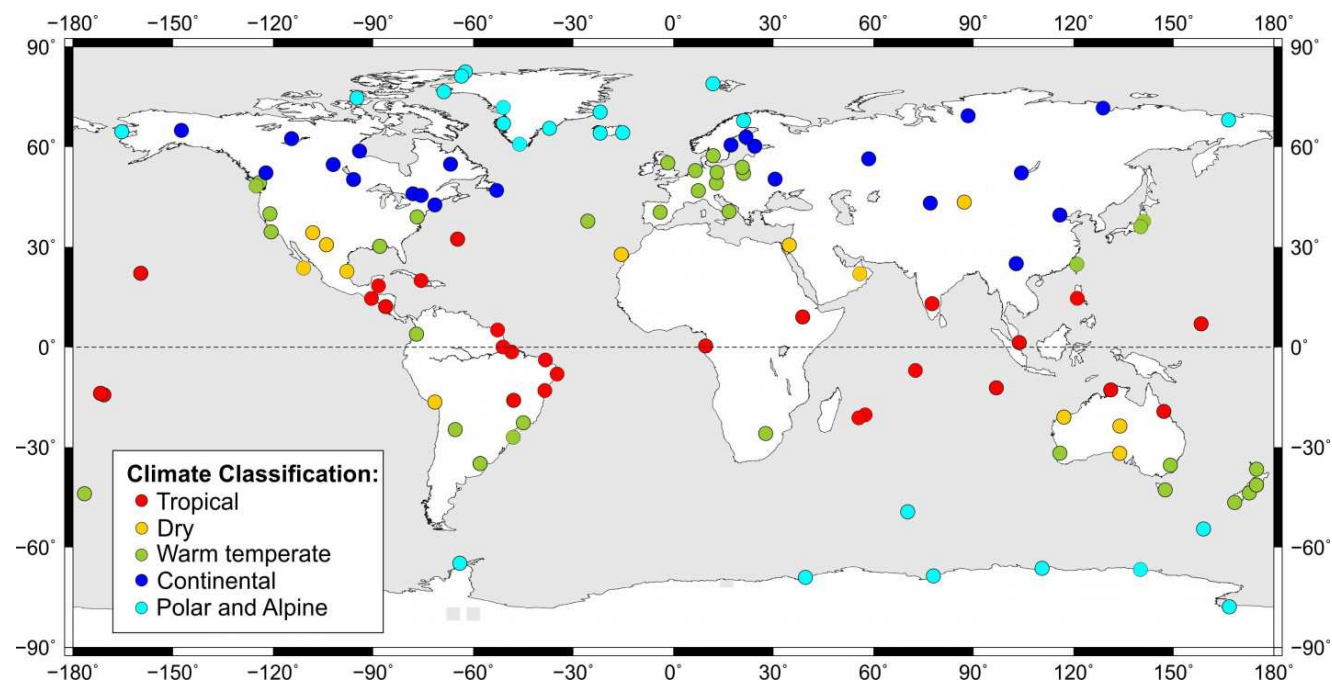

Figure 2: Globally distributed 120 stations are sub-divided into five different climate zones based on Köppen-Geiger general climate classification: tropical (red), dry (yellow), warm temperate (green), continental (dark blue) and polar and Alpine (light blue). 
Atmos. Meas. Tech. Discuss., doi:10.5194/amt-2016-385, 2016

Manuscript under review for journal Atmos. Meas. Tech.

Published: 6 December 2016

(c) Author(s) 2016. CC-BY 3.0 License.

\section{Atmospheric \\ Measurement \\ Techniques}

Discussions

(c) $\underset{\mathrm{BY}}{(\mathrm{P})}$

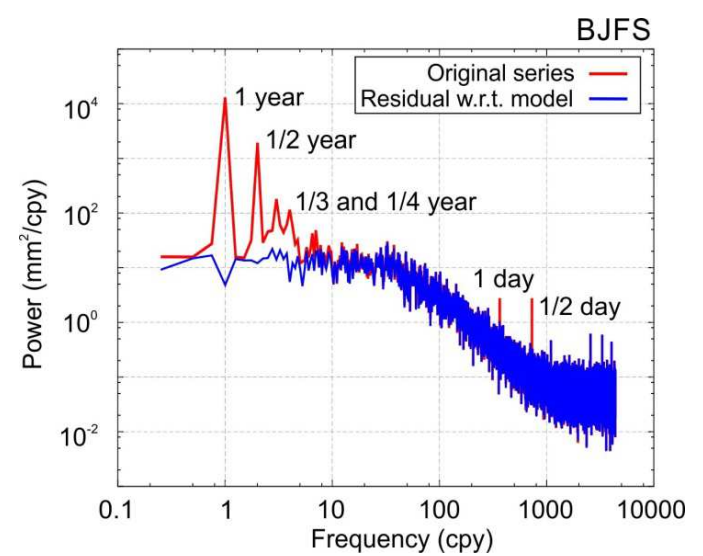

Figure 3: PSD of ZTD for BJFS (Beijing, China). Peaks at annual, semi-annual, 3- and 4-monthly as well as daily and sub-daily frequencies can be easily identified in the plot. The power of the original series is plotted in red, while the power of residuals with respect to the model from equation (2) is in blue. Remaining peaks in high frequencies were found to be non-significant.

5

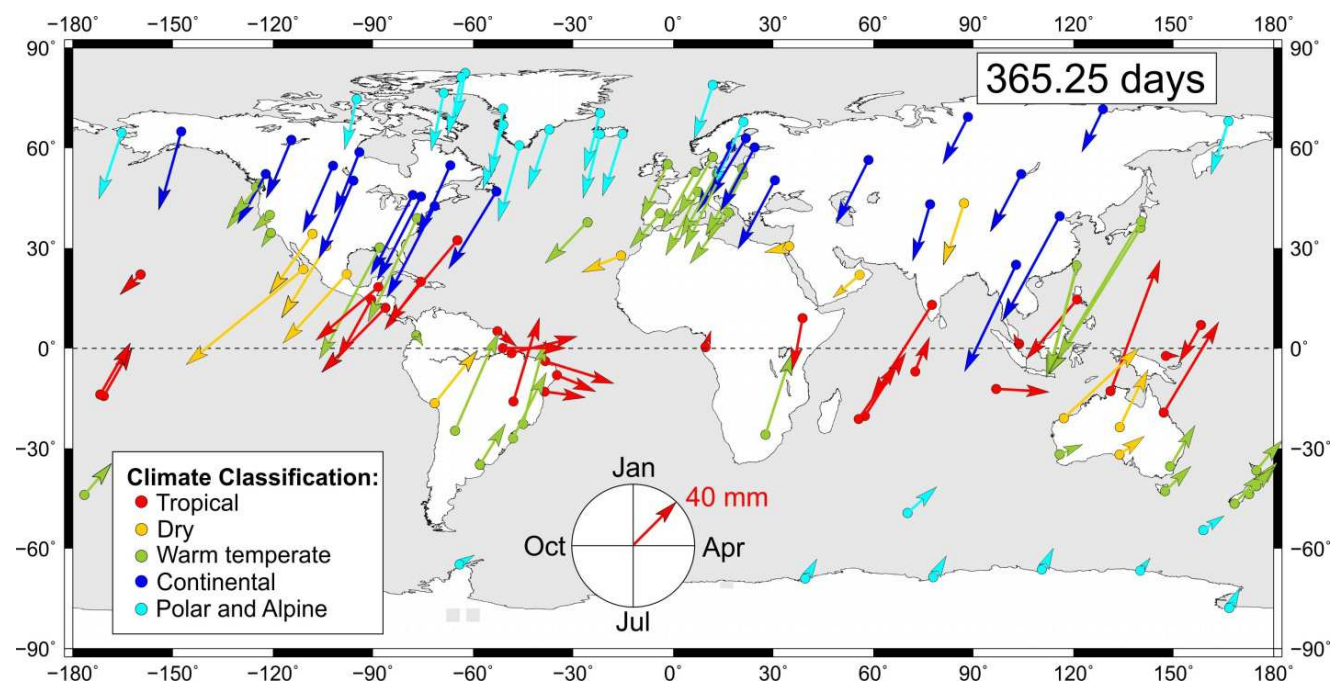

Figure 4: Annual amplitudes for 120 selected stations. Stations are classified into five different climate zones as in Figure 2. The length of arrow depicts the amplitude of the annual sine curve with a reference to $40 \mathrm{~mm}$. Phase shifts are counted as clockwise beginning from the North which means positive peak in January. 
Atmos. Meas. Tech. Discuss., doi:10.5194/amt-2016-385, 2016

Manuscript under review for journal Atmos. Meas. Tech.

Published: 6 December 2016

(c) Author(s) 2016. CC-BY 3.0 License.

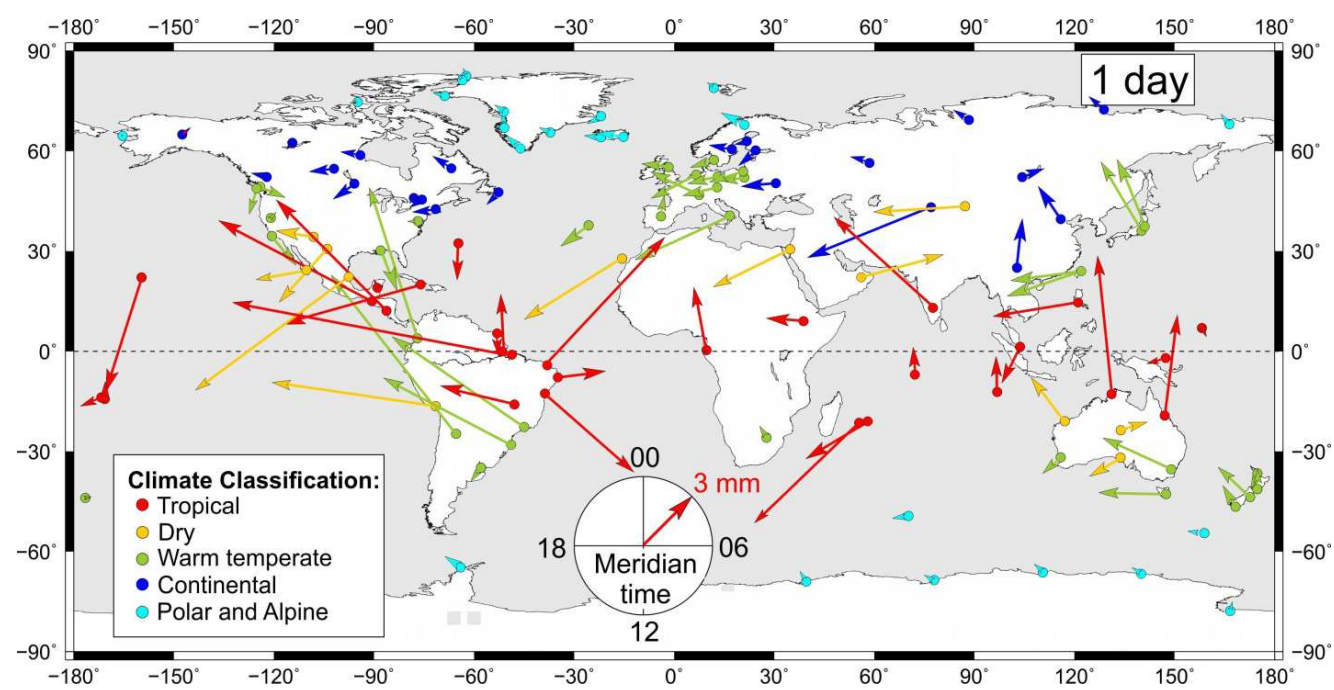

Figure 5: Diurnal amplitudes for 120 selected stations. Stations are classified into five different climate zones as in Figure 2. The length of arrow depicts the amplitude of diurnal curve with a reference to $3 \mathrm{~mm}$. Phase shifts are counted as clockwise beginning from the North which means positive peak at 0 hours with respect to the local meridian.
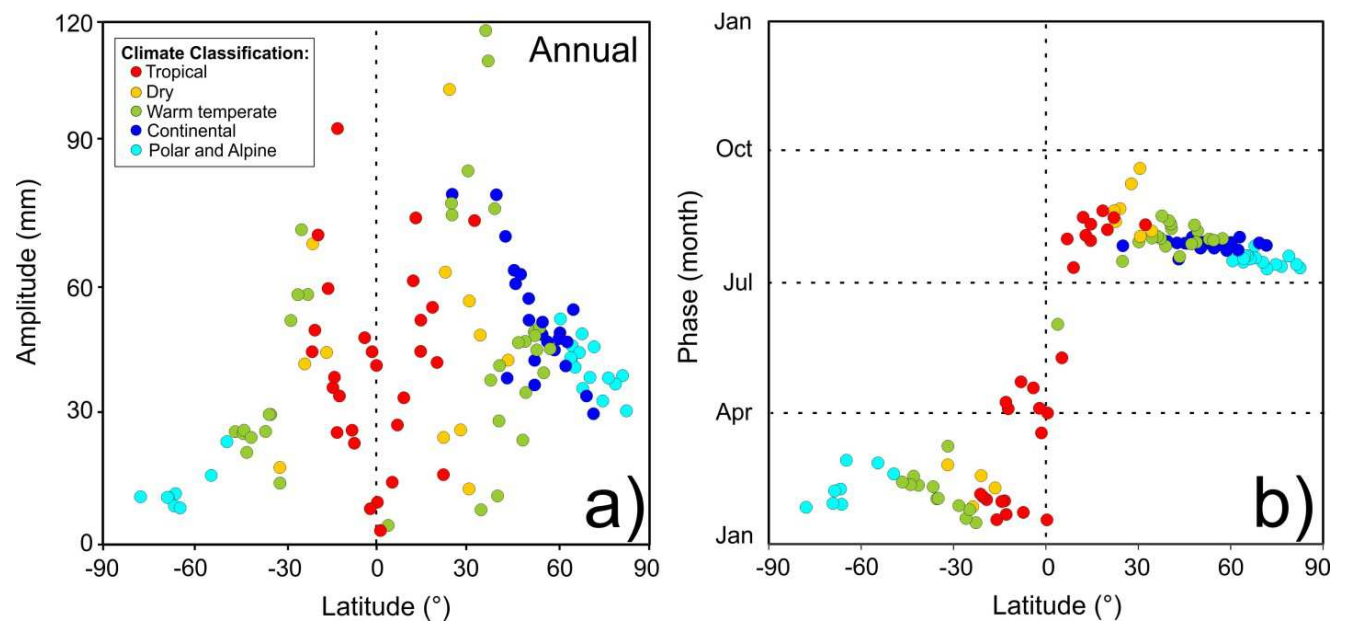

Figure 6: (a) Annual amplitudes (mm) of 120 selected stations w.r.t latitude. (b) Phase shifts (given in month) of 120 selected stations w.r.t latitude. 
Atmos. Meas. Tech. Discuss., doi:10.5194/amt-2016-385, 2016

Manuscript under review for journal Atmos. Meas. Tech.

Published: 6 December 2016
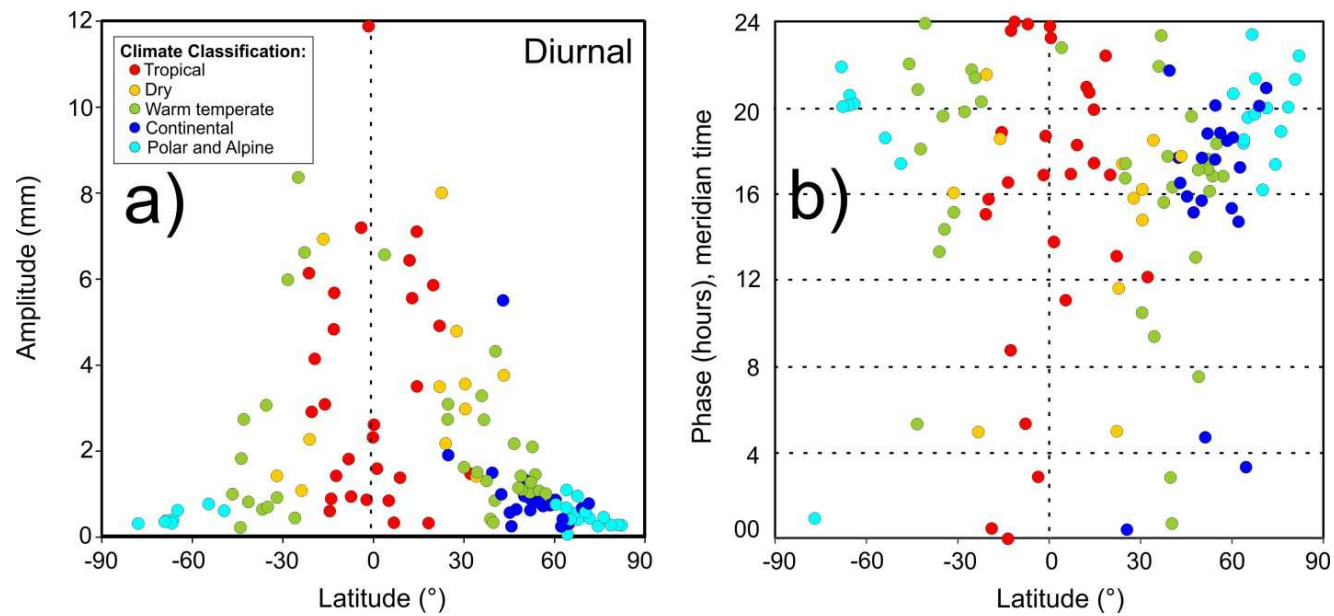

Figure 7: (a) Diurnal amplitudes (mm) of 120 selected stations w.r.t latitude. (b) Phase shifts (given in hours) of 120 selected stations w.r.t latitude. 
Atmos. Meas. Tech. Discuss., doi:10.5194/amt-2016-385, 2016

Manuscript under review for journal Atmos. Meas. Tech.

Published: 6 December 2016

(c) Author(s) 2016. CC-BY 3.0 License.

\section{Atmospheric Measurement Techniques \\ Discussions}
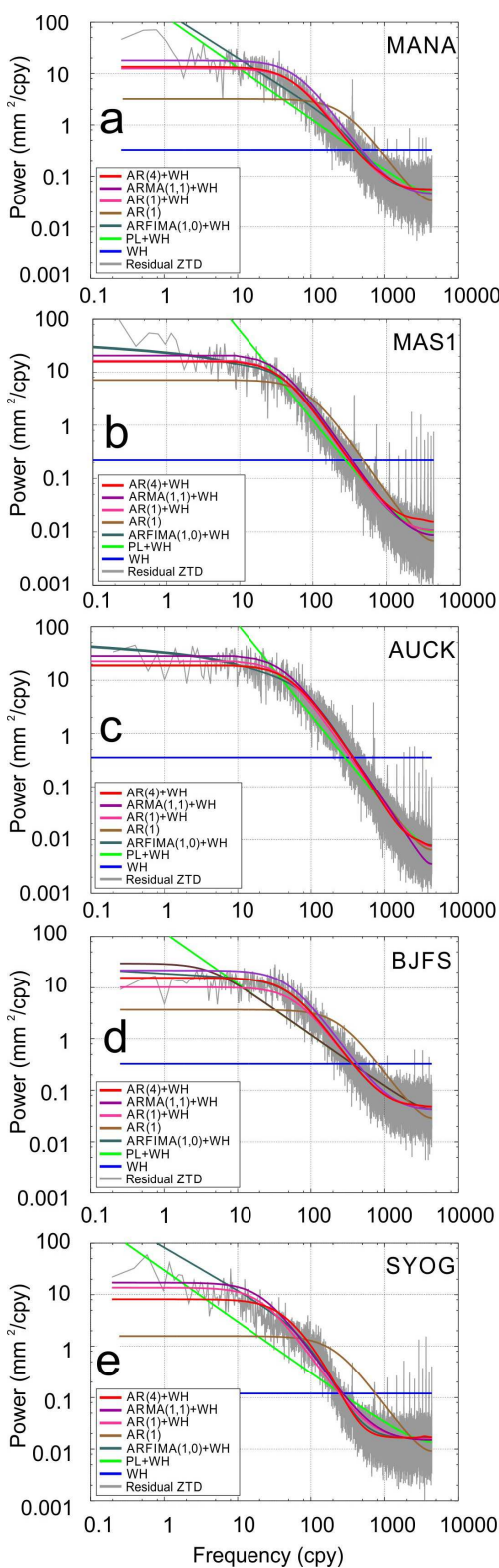

Figure 8: Examples of power spectra of five stations from different five climate zones. (a) tropical: MANA, Managua, Nicaragua. (b) dry: MAS1, Gran Canaria, Spain. (c) warm temperate: AUCK, New Zealand. (d) continental: BJFS, Beijing, China. (e) polar 5 and Alpine: SYOG, Syowa, Antarctica. Different noise models: WH (blue), PL+WH (light green), ARFIMA(1,0)+WH (turquoise), AR(1) (brown), AR(1)+WH (pink), ARMA(1,1)+WH (violet) and AR(4)+WH (Red) were fitted into residuals (grey). 
Atmos. Meas. Tech. Discuss., doi:10.5194/amt-2016-385, 2016

Manuscript under review for journal Atmos. Meas. Tech.

Published: 6 December 2016

(c) Author(s) 2016. CC-BY 3.0 License.
Atmospheric

Measurement

Techniques

Discussions

(c) (1)

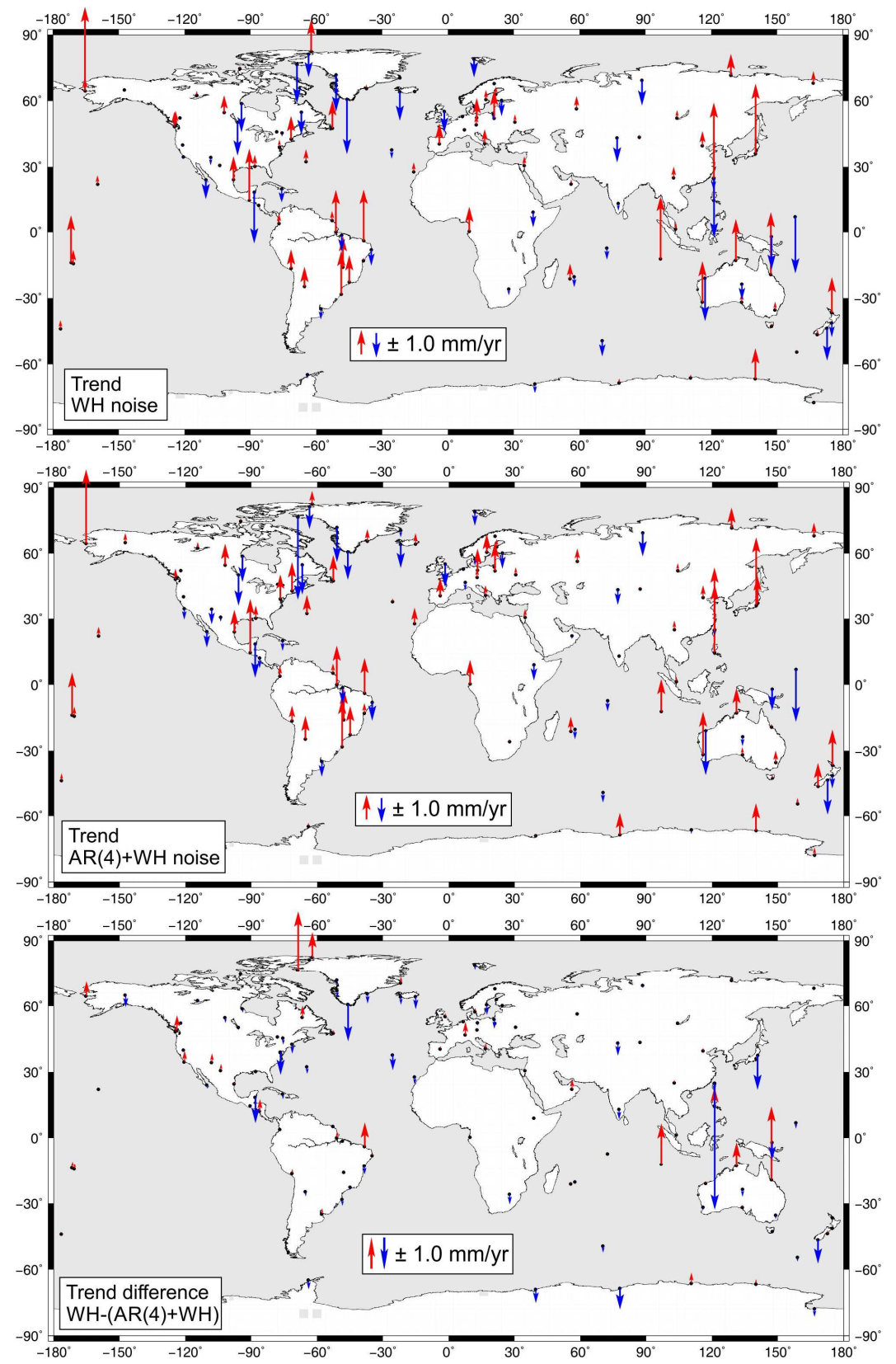

Figure 9: Values of trends $(\mathrm{mm} / \mathrm{yr})$ and a difference in trends $(\mathrm{mm} / \mathrm{yr})$ when pure white noise $(\mathrm{WH})$ and the combination of autoregressive and white noise $(\mathrm{AR}(4)+\mathrm{WH})$ processes are being assumed. 
Atmos. Meas. Tech. Discuss., doi:10.5194/amt-2016-385, 2016

Manuscript under review for journal Atmos. Meas. Tech.

Published: 6 December 2016

(C) Author(s) 2016. CC-BY 3.0 License.

\section{Atmospheric Measurement \\ Techniques}

Discussions

(c) (i)

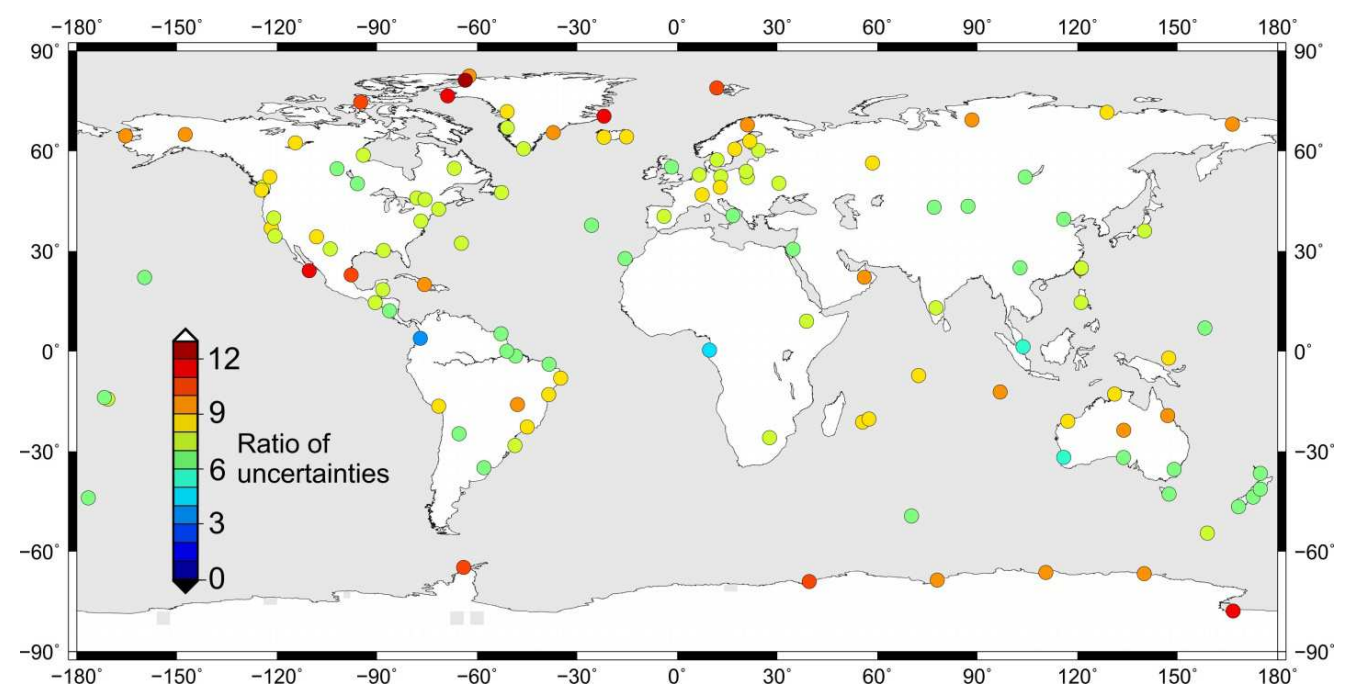

Figure 10: Ratio of trend uncertainties estimated with $\mathrm{AR}(4)+\mathrm{WH}$ and WH-only noise model, see Table S2 for more details. 
Atmos. Meas. Tech. Discuss., doi:10.5194/amt-2016-385, 2016

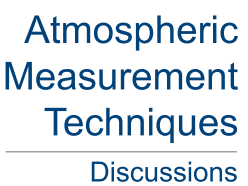

Manuscript under review for journal Atmos. Meas. Tech.

Published: 6 December 2016

(c) Author(s) 2016. CC-BY 3.0 License.

Discussions

(c) (i)

Table 1. Median annual and diurnal amplitudes $(\mathrm{mm})$ for each of five climate zones considered in this study.

\begin{tabular}{|c|c|c|}
\hline Climate zone & Median annual amplitude (mm) & Median diurnal amplitude (mm) \\
\hline Tropical & $42.0 \pm 0.8$ & $2.9 \pm 0.8$ \\
\hline Dry & $43.4 \pm 0.8$ & $3.2 \pm 0.8$ \\
\hline Warm temperate & $41.3 \pm 0.8$ & $1.4 \pm 0.8$ \\
\hline Continental & $48.6 \pm 0.8$ & $0.8 \pm 0.8$ \\
\hline Polar and Alpine $(\mathrm{NH})$ & $40.9 \pm 0.8$ & $0.4 \pm 0.8$ \\
\hline Polar and Alpine $(\mathrm{SH})$ & $11.5 \pm 0.8$ & $0.4 \pm 0.8$ \\
\hline
\end{tabular}


Atmos. Meas. Tech. Discuss., doi:10.5194/amt-2016-385, 2016

Atmospheric

Manuscript under review for journal Atmos. Meas. Tech.

Measurement

Techniques

(c) Author(s) 2016. CC-BY 3.0 License.

Discussions

(c) (i)

Table 2. Trends and uncertainties $(\mathrm{mm} / \mathrm{yr})$ for different noise models tested in this study. Five stations are juxtaposed: MANA, MAS1, AUCK, BJFS and SYOG, that represent five different climate zones: tropical, dry, warm temperate, continental and polar and Alpine, respectively. The selection of the best noise model was based on BIC and MLE values. The optimal model minimizes BIC and maximizes MLE are in bold.

\begin{tabular}{|c|c|c|c|c|c|c|c|c|}
\hline \multirow{2}{*}{ Noise } & \multicolumn{4}{|c|}{ (a) MANA, Managua, Nicaragua } & \multicolumn{4}{|c|}{ (b) MAS1, Maspalomas, Gran Canaria, Spain } \\
\hline & Trend & Error & BIC & MLE & Trend & Error & BIC & MLE \\
\hline WH & -0.03 & 0.11 & 1360907 & -680423 & 0.32 & 0.05 & 1763497 & -881712 \\
\hline $\mathrm{PL}+\mathrm{WH}$ & -0.35 & 2.10 & 1195210 & -597572 & 3.44 & 3.14 & 1355913 & -677918 \\
\hline ARFIMA(1,0)+WH & -0.35 & 2.04 & 1192072 & -596002 & 1.03 & 0.44 & 1354127 & -677025 \\
\hline $\mathrm{AR}(1)$ & -0.35 & 0.30 & 1213441 & -606689 & 0.82 & 0.27 & 1372466 & -686196 \\
\hline $\mathrm{AR}(1)+\mathrm{WH}$ & -0.35 & 0.50 & 1192131 & -596033 & 0.89 & 0.40 & 1354168 & -677046 \\
\hline ARMA(1,1)+WH & -0.35 & 0.50 & 1192133 & -596033 & 0.89 & 0.40 & 1354170 & -677046 \\
\hline $\mathbf{A R}(4)+W H$ & -0.35 & 0.69 & 1192091 & -596009 & 0.53 & 0.32 & 1354091 & -677004 \\
\hline \multirow{2}{*}{ Noise } & \multicolumn{4}{|c|}{ (c) AUCK, Whangaparaoa Peninsula, New Zealand } & \multicolumn{4}{|c|}{ (d) BJFS, Beijing China } \\
\hline & Trend & Error & BIC & MLE & Trend & Error & BIC & MLE \\
\hline WH & 1.29 & 0.08 & 1788817 & -894370 & 0.49 & 0.07 & 1411515 & -705726 \\
\hline $\mathrm{PL}+\mathrm{WH}$ & -1.83 & 5.49 & 1325702 & -662609 & 0.62 & 1.93 & 1224722 & -612328 \\
\hline ARFIMA(1,0)+WH & 0.79 & 0.93 & 1320723 & -660320 & 0.53 & 0.29 & 1217661 & -608795 \\
\hline $\mathrm{AR}(1)$ & 1.40 & 0.56 & 1322653 & -661287 & 0.53 & 0.27 & 1243013 & -621475 \\
\hline $\mathrm{AR}(1)+\mathrm{WH}$ & 1.33 & 0.60 & 1321365 & -660642 & 0.53 & 0.26 & 1217677 & -608805 \\
\hline ARMA $(1,1)+\mathrm{WH}$ & 1.33 & 0.60 & 1321367 & -660642 & 0.53 & 0.26 & 1217679 & -608805 \\
\hline $\mathbf{A R}(4)+W H$ & 1.29 & 0.50 & 1320626 & -660270 & 0.41 & 0.49 & 1217664 & -608798 \\
\hline \multirow{2}{*}{ Noise } & \multicolumn{4}{|c|}{ (e) SYOG, Syowa, Antarctica } & & & & \\
\hline & Trend & Error & BIC & MLE & & & & \\
\hline WH & -0.31 & 0.03 & 1638636 & -819283 & & & & \\
\hline $\mathrm{PL}+\mathrm{WH}$ & 1.10 & 0.89 & 1357870 & -678898 & & & & \\
\hline ARFIMA $(1,0)+W H$ & 1.59 & 1.11 & 1340947 & -670435 & & & & \\
\hline $\mathrm{AR}(1)$ & -0.29 & 0.11 & 1398359 & -699143 & & & & \\
\hline $\mathrm{AR}(1)+\mathrm{WH}$ & 0.06 & 0.30 & 1342770 & -671348 & & & & \\
\hline ARMA $(1,1)+\mathrm{WH}$ & 0.06 & 0.30 & 1342772 & -671348 & & & & \\
\hline $\mathrm{AR}(4)+\mathrm{WH}$ & 0.06 & 0.30 & 1340825 & -670372 & & & & \\
\hline
\end{tabular}


Atmos. Meas. Tech. Discuss., doi:10.5194/amt-2016-385, 2016

Atmospheric

Manuscript under review for journal Atmos. Meas. Tech.

Measurement

Published: 6 December 2016

Techniques

(c) Author(s) 2016. CC-BY 3.0 License.

Discussions

Table 3. The median values of noise parameters for each of five climate zones considered in this study. The associated error bound of median amplitudes of noise and median fraction of AR are the 1-IQR (Inter-Quartile Range) values. The associated error bounds of median coefficients are the 1- $\sigma$ standard deviations.

\begin{tabular}{|c|c|c|c|c|}
\hline \multicolumn{5}{|c|}{ Median amplitudes of noise $(\mathrm{mm}) \pm 1-I Q R$} \\
\hline Climate zone & \multicolumn{2}{|c|}{$\mathbf{W N}$} & \multicolumn{2}{|c|}{$\mathbf{A R}$} \\
\hline Tropical & \multicolumn{2}{|c|}{$13.00 \pm 5.67$} & \multicolumn{2}{|c|}{$9.59 \pm 8.12$} \\
\hline Dry & \multicolumn{2}{|c|}{$9.23 \pm 6.18$} & \multicolumn{2}{|c|}{$6.80 \pm 5.72$} \\
\hline Warm temperate & \multicolumn{2}{|c|}{$9.70 \pm 8.28$} & \multicolumn{2}{|c|}{$8.75 \pm 7.93$} \\
\hline Continental & \multicolumn{2}{|c|}{$8.77 \pm 7.62$} & \multicolumn{2}{|c|}{$7.07 \pm 6.03$} \\
\hline $\begin{array}{l}\text { Polar and Alpine } \\
(\mathrm{NH})\end{array}$ & \multicolumn{2}{|c|}{$7.17 \pm 6.45$} & \multicolumn{2}{|c|}{$4.85 \pm 4.06$} \\
\hline $\begin{array}{l}\text { Polar and Alpine } \\
(\mathrm{SH})\end{array}$ & \multicolumn{2}{|c|}{$8.91 \pm 8.05$} & \multicolumn{2}{|c|}{$4.07 \pm 3.60$} \\
\hline \multicolumn{5}{|c|}{ Median coefficients of AR(4) $\pm 1-\sigma$} \\
\hline Climate zone & $\mathbf{A R}(\mathbf{1})$ & $\mathbf{A R}(2)$ & $\mathbf{A R}(3)$ & $\mathbf{A R}(4)$ \\
\hline Tropical & $0.90 \pm 0.08$ & $0.05 \pm 0.08$ & $0.01 \pm 0.03$ & $0.03 \pm 0.01$ \\
\hline Dry & $0.78 \pm 0.04$ & $0.19 \pm 0.03$ & $0.05 \pm 0.01$ & $0.01 \pm 0.01$ \\
\hline Warm temperate & $0.72 \pm 0.03$ & $0.17 \pm 0.02$ & $0.08 \pm 0.01$ & $-0.01 \pm 0.01$ \\
\hline Continental & $0.80 \pm 0.02$ & $0.08 \pm 0.01$ & $0.09 \pm 0.01$ & $-0.03 \pm 0.01$ \\
\hline $\begin{array}{c}\text { Polar and Alpine } \\
(\mathrm{NH})\end{array}$ & $0.61 \pm 0.02$ & $0.27 \pm 0.01$ & $0.11 \pm 0.01$ & $-0.02 \pm 0.01$ \\
\hline $\begin{array}{c}\text { Polar and Alpine } \\
(\mathrm{SH})\end{array}$ & $0.61 \pm 0.01$ & $0.28 \pm 0.01$ & $0.13 \pm 0.01$ & $0.01 \pm 0.01$ \\
\hline \multicolumn{5}{|c|}{ Median fraction of $\mathrm{AR} \pm 1-\mathrm{IQR}$} \\
\hline \multicolumn{5}{|l|}{ Climate zone } \\
\hline Tropical & \multicolumn{4}{|c|}{$0.33 \pm 0.22$} \\
\hline Dry & \multicolumn{4}{|c|}{$0.30 \pm 0.23$} \\
\hline Warm temperate & \multicolumn{4}{|c|}{$0.44 \pm 0.37$} \\
\hline Continental & \multicolumn{4}{|c|}{$0.40 \pm 0.31$} \\
\hline $\begin{array}{c}\text { Polar and Alpine } \\
(\mathrm{NH})\end{array}$ & \multicolumn{4}{|c|}{$0.26 \pm 0.21$} \\
\hline $\begin{array}{c}\text { Polar and Alpine } \\
(\mathrm{SH})\end{array}$ & \multicolumn{4}{|c|}{$0.21 \pm 0.18$} \\
\hline
\end{tabular}

